\title{
SUSTAINED INTRA-ARTICULAR DELIVERY OF IL-1RA FROM A THERMALLY-RESPONSIVE ELASTIN-LIKE POLYPEPTIDE AS A THERAPY FOR POST-TRAUMATIC ARTHRITIS
}

\author{
K.A. Kimmerling ${ }^{1,2}$, B.D. Furman ${ }^{1}$, D.S. Mangiapani ${ }^{1}$, M.A. Moverman ${ }^{2}$, S.M. Sinclair ${ }^{2}$, J.L. Huebner ${ }^{3}$, A. Chilkoti², \\ V.B. Kraus ${ }^{3,4}$, L.A. Setton ${ }^{2,1}$, F. Guilak ${ }^{1,2, \S}$ and S.A. Olson ${ }^{2, *, \S}$ \\ ${ }^{1}$ Department of Orthopaedic Surgery, Duke University Medical Center, Durham, NC, USA \\ ${ }^{2}$ Department of Biomedical Engineering, Duke University, Durham, NC, USA \\ ${ }^{3}$ Duke Molecular Physiology Institute, Durham, NC, USA \\ ${ }^{4}$ Department of Medicine, Duke University Medical Center, Durham, NC, USA
}

${ }^{\S}$ These authors contributed equally.

\begin{abstract}
Post-traumatic arthritis (PTA) is a rapidly progressive form of arthritis that develops due to joint injury, including articular fracture. Current treatments are limited to surgical restoration and stabilization of the joint; however, evidence suggests that PTA progression is mediated by the upregulation of pro-inflammatory cytokines, such as interleukin-1 (IL-1) or tumor necrosis factor- $\alpha$ (TNF- $\alpha$ ). Although these cytokines provide potential therapeutic targets for PTA, intra-articular injections of anti-cytokine therapies have proven difficult due to rapid clearance from the joint space. In this study, we examined the ability of a cross-linked elastin-like polypeptide (xELP) drug depot to provide sustained intra-articular delivery of IL-1 and TNF- $\alpha$ inhibitors as a beneficial therapy. Mice sustained a closed intra-articular tibial plateau fracture; treatment groups received a single intra-articular injection of drug encapsulated in xELP. Arthritic changes were assessed 4 and 8 weeks after fracture. Inhibition of IL-1 significantly reduced the severity of cartilage degeneration and synovitis. Inhibition of TNF- $\alpha$ alone or with IL-1 led to deleterious effects in bone morphology, articular cartilage degeneration, and synovitis. These findings suggest that IL-1 plays a critical role in the pathogenesis of PTA following articular fracture, and sustained intra-articular cytokine inhibition may provide a therapeutic approach for reducing or preventing joint degeneration following trauma.
\end{abstract}

Keywords: Arthritis, murine model, cartilage, drug delivery, inflammation.

\footnotetext{
*Address for correspondence:

Steven A. Olson, M.D.

Duke University Medical Center

Box 3389

Durham, NC 27710

USA
}

Telephone Number: 1-919-668-3000

FAX Number: 1-919-668-2933

E-mail: olson016@mc.duke.edu

\section{Introduction}

Post-traumatic arthritis (PTA) is a progressive and degenerative form of arthritis that develops following joint trauma (Brown et al., 2006). Most commonly, joint trauma can be incurred by excessive loading of a synovial joint, tears of the meniscus, ligament, or capsule, joint dislocation, or an articular fracture. Currently, $12 \%$ of the 27 million Americans that suffer from osteoarthritis (OA) are believed to have PTA (Brown et al., 2006; Lawrence et al., 2008). An excess burden of PTA is observed in military populations, wherein OA after joint injury is the leading cause of disability that prevents soldiers from remaining on active duty (Patzkowski et al., 2012). The rate of developing PTA in weight-bearing joints after combat injuries is $60 \%$, with a $100 \%$ incidence rate for knee joints following trauma or injury (Rivera et al., 2012). The total economic burden of PTA has been estimated to exceed $\$ 3$ billion in direct health care expenses annually (Brown et al., 2006).

Of all types of joint trauma, intra-articular fractures most commonly lead to PTA, despite surgical restoration and stabilization of the joint (Buckwalter and Brown, 2004). Articular fractures are complex injuries that occur as a result of excessive, traumatic loading that can cause damage in the bone, soft tissue, synovium, and vascular regions (Cole et al., 2009; Furman et al., 2006). Following injury, inflammatory cytokines and chemokines are elevated in synovial fluid (Bigoni et al., 2013; Cameron et al., 1997; Elsaid et al., 2009; Higuchi et al., 2006; Irie et al., 2003; Lewis et al., 2013; Marks and Donaldson, 2005; Mountziaris and Mikos, 2008; Sward et al., 2012). Of these cytokines, interleukin-1 (IL-1) and tumor necrosis factor alpha (TNF- $\alpha)$ are typically found at the site of injury after trauma and aid in recruiting other cytokines and chemokines, such as IL-6 and IL-8, necessary to the healing process (Abramson and Yazici, 2006; Fazzalari, 2011; Fernandes et al., 2002). However, IL-1 and TNF- $\alpha$ also exhibit a chondro-destructive effect on cartilage by stimulating the release of other cytokines and enzymes, such as matrix metalloproteinases and aggrecanases, that break down articular cartilage (Fukui et al., 2001; Marks and Donaldson, 2005; McNulty et al., 2013). Rapid upregulation of IL- 1 and TNF- $\alpha$ was shown in a previous murine articular fracture study, with IL-1 $\beta$ upregulated 750 -fold hours after fracture, IL-1 $\alpha$ upregulated 7-fold one 
day after fracture, and TNF- $\alpha$ upregulated 13-fold one day after fracture (Lewis et al., 2013).

The role of IL-1 and TNF- $\alpha$ in inflammatory arthritis has been extensively studied; currently, there are several commercially available cytokine inhibitors for the treatment of rheumatic diseases. Interleukin-1 Receptor antagonist (IL-1Ra, anakinra, Kineret ${ }^{\mathbb{R}}$ ) is FDA approved for the treatment of rheumatoid arthritis (RA). IL-1Ra works by competitively binding to the IL-1 receptor (IL-1R) and attenuating the signaling associated with IL-1/IL-1R binding. Similarly, soluble tumor necrosis factor receptor II (sTNFRII, etanercept, Enbrel ${ }^{\circledR}$ ) is FDA approved for use with RA patients. sTNFRII is a soluble fragment of the TNF receptor that competitively binds TNF- $\alpha$ and TNF- $\beta$ in the extracellular space, thus preventing their binding to the membrane-bound TNF receptor. The results of past clinical studies have shown some efficacy in RA patients when IL-1Ra was delivered systemically (Bresnihan et al., 1998; Fleischmann, 2006; Fleischmann et al., 2003b; Fleischmann et al., 2006b; Nuki et al., 2002) and when sTNFRII was delivered locally (Bliddal et al., 2006; Boesen et al., 2008; Fiocco et al., 2010; Roux et al., 2011) or systemically (Bathon et al., 2006; Fleischmann et al., 2006a; Fleischmann et al., 2003a; Johnsen et al., 2006; Kavanaugh et al., 2008; Krieckaert et al., 2012; Moreland et al., 1999).

While local or systemic delivery of IL-1Ra or sTNFRII has been established to provide efficacy against RA, less is known of the potential for local cytokine antagonism to modify disease or symptoms in patients affected by OA, particularly in isolated joints. For example, an intra-articular injection of IL-1Ra into the knee joint improved symptoms in patients with established OA over the course of $4 \mathrm{~d}$ (Chevalier et al., 2005; Chevalier et al., 2009), although the improvements with joint injection diminished to control levels over time. The short duration of the efficacy of IL-1Ra in this study was attributed to its brief intra-articular half-life, which is of the order of 2-6 h (Chevalier et al., 2009). Nonetheless, if administered after joint trauma, a single intra-articular injection of IL-1Ra was shown to improve short-term knee pain and function scores (Kraus et al., 2012). For OA, the use of etanercept has not been documented; however, systemic administration of two other anti-TNF drugs (infliximab and adalimumab) has been shown to provide a modest improvement in symptoms for patients with hand OA (Guler-Yuksel et al., 2010; Magnano et al., 2007). Because of the potential pro-inflammatory role of IL- 1 and TNF- $\alpha$ in arthritis, and the success of both IL-1 and TNF inhibitors, subsequent studies have included groups that administer both drugs at the same time. For example, in a TNF-induced murine arthritis model, the systemic administration of IL-1Ra, anti-TNF, or a combination of both IL-1Ra and anti-TNF was examined. Synovial inflammation, bone erosion, and cartilage degeneration were blocked by both anti-TNF and combination therapy (Zwerina et al., 2004). However, such an approach has not been examined as a therapy for intra-articular fracture, which involves a complex cascade of bone and soft tissue damage and inflammation leading to PTA (Furman et al., 2006; Furman et al., 2007; Lewis et al., 2013). Our previous research indicated that a single intra-articular injection of IL-1Ra reduced, but did not completely eliminate the manifestations of PTA after a closed articular fracture (Furman et al., 2014b; Mangiapani et al., 2012).

Local intra-articular administration to the knee joint through use of sustained-release depots is advantageous for the ability to deliver relatively high total drug doses, while minimizing the peak drug concentration in systemic circulation and allowing therapeutic drug doses over prolonged times (Evans et al., 2014; Larsen et al., 2008). Previous work by Gorth and co-authors have shown that the release of IL-1Ra from poly(lactic-co-glycolic acid) microspheres helped to reduce degradation of the nucleus pulposus caused by IL-1 $\beta$ (Gorth et al., 2012). Elastin-like polypeptides (ELPs) have demonstrated value as injectable drug depots that can provide for local, sustained release of drugs in the knee joint (Allen et al., 2011; Allen et al., 2010; Shamji et al., 2007). ELPs are pentapeptide sequences from native human elastin (V-P-G-X-G, where X is any amino acid) (Urry, 1992; Urry et al., 1998) with a history of medical applications that illustrate their biocompatible and non-immunogenic properties (Adams et al., 2009; Betre et al., 2006a; Chilkoti et al., 2002a; Chilkoti et al., 2002b; MacEwan and Chilkoti, 2009; Megeed et al., 2002; Nettles et al., 2010; Tejeda-Montes et al., 2012). ELPs undergo an inverse phase transition, wherein they are soluble in aqueous solutions below a specific transition temperature $\left(T_{t}\right)$ and become insoluble above $T_{t}$ (Urry, 1997). This phase transition causes the formation of self-associating particles that can entrap drug when the temperature is raised above $T_{t}$; when $T_{t}$ is targeted below body temperature, the injected ELP can spontaneously form a depot for prolonged drug release in the body (Adams et al., 2009; Betre et al., 2006a; Meyer and Chilkoti, 2002; Shamji et al., 2007). While prior studies have largely relied upon conjugation of drug to the ELP prior to depot formation, entrapment of drug in ELP is an alternate possibility. Adams and co-workers found ELP entrapment of antibiotics may be improved following inter-ELP crosslinking that promotes cohesion in the depot formation (Adams et al., 2009). This strategy is attractive also for large molecule protein drugs for the benefit that entrapment preserves the structure and function of the native protein drug.

For this study, we hypothesized that sustained local (intra-articular) inhibition of IL-1, TNF- $\alpha$, or both IL-1 and TNF- $\alpha$ together would prevent the development of PTA following articular fracture. The objective of this study was to locally deliver a drug-containing ELP depot to inhibit intra-articular inflammation following trauma using a closed articular fracture model in the tibial plateau of mice. The severity of arthritic changes in mouse knee joints was assessed from histologic analysis of joint tissues, bone morphologic changes from microCT, and biomarkers from serum and synovial fluid, and compared amongst single injections of depot-delivered IL-1Ra, sTNFRII, or the dual combination to identify the most promising treatment option. 


\section{Materials and Methods}

\section{ELP production and encapsulation}

One ELP sequence, VPGKG(VPGVG) 16 -102, termed KV16-102 (MW 42.7 kDa), was chosen for this study as described previously (Adams et al., 2009; Meyer and Chilkoti, 2002; Trabbic-Carlson et al., 2003). In brief, an expression vector containing the coding ELP gene was transformed into E. coli BLR(DE3) (Novagen, Madison, WI, USA) for protein hyperexpression using previously established procedures. ELP was purified by successive thermal cycling, passed through a sterile filter, and resuspended in PBS at $150 \mathrm{mg} / \mathrm{mL}$ before use. For each ELP drug-loading construct to be used in animal studies, $80 \mu \mathrm{L}$ of ELP solution was mixed with an organophosphorous cross-linker, $\beta$-[tris(hydroxymethyl) phosphino]propionic acid (THPP), an amine-reactive crosslinker at a 1:1 molar ratio of ELP amines to THPP sites (Lim et al., 2007; Lim et al., 2008; Nettles et al., 2010). The mixture was placed on a shaker at $4{ }^{\circ} \mathrm{C}$ for $30 \mathrm{~min}$, and then allowed to crosslink at $37^{\circ} \mathrm{C}$ for $24 \mathrm{~h}$. The cross-linked ELP (xELP) was lyophilized, quenched in a sterile cell culture hood, and then re-lyophilized. At $37^{\circ} \mathrm{C}$, it has been shown that these cross-linked ELPs will undergo a transition to a gel-like phase with a change in opacity of the ELP construct, thus preserving much of the thermally-induced transition properties of the unmodified ELPs (Adams et al., 2009). Drug loading into lyophilized $\mathrm{xELP}$ constructs was performed by rehydrating the xELP in $80 \mu \mathrm{L}$ of a drug-containing solution (or phosphatebuffered saline (PBS) for control) to yield the final drug concentrations in a $6 \mu \mathrm{L}$ injection as follows: $x E L P[I L-$ $1 \mathrm{Ra}]=0.45 \mathrm{mg}$ of IL-1Ra; $x$ ELP[sTNFRII $]=0.15 \mathrm{mg}$ of sTNFRII; xELP[IL-1Ra+sTNFRII] $=0.45 \mathrm{mg}$ of IL-1Ra and $0.15 \mathrm{mg}$ of sTNFRII; xELP[PBS] received only PBS. Constructs for both the in vitro and in vivo experiments were prepared the same, with the exception that the constructs prepared for the in vivo experiment were done under sterile conditions.

\section{In vitro release of drug from $x E L P$}

In vitro drug release profiles of both IL-1Ra and sTNFRII were quantified as described below. Lyophilized xELP depots (12 mg ELP protein) were rehydrated in either PBS (xELP[PBS]), IL-1Ra (xELP[IL-1Ra], anakinra), or sTNFRII (xELP[sTNFRII], etanercept) and incubated in either PBS or $10 \%$ serum-containing medium (10\% fetal bovine serum (FBS) in PBS) to determine the release of each drug over $7 \mathrm{~d}$. For samples in PBS, protein absorbance at $280 \mathrm{~nm}$ was used to quantify the concentration of released drug. In order to account for any release of uncross-linked ELP, the absorbance of xELP[PBS] was measured at each time point to serve as an experimental "blank." The molar extinction coefficients for both IL$1 \mathrm{Ra}$ and sTNFRII were used at each time point, along with the Beers-Lambert Law in order to quantify drug concentrations in the supernatant at each time point. For the serum-containing medium, absorbance could not be used to quantify drug release, so human IL-1Ra and sTNFRII ELISAs were used (DRA00B and DRT200, R\&D Systems,
Minneapolis, MN, USA). For each ELISA, xELP[PBS] samples were measured as controls to ensure that there was no background interference from ELP fragments released by esterases or proteases in FBS.

\section{In vivo drug release assays}

In vivo release profiles for both IL-1Ra and sTNFRII were obtained using serial collections of serum from mice. Blood was collected at day 1, 5, 14, 21, 28, 42 and 56 following fracture. All serum samples from a single group and collection day were pooled $(n=6-11$ per group per time point) in order to obtain sufficient fluid volumes for detection of IL-1Ra (minimum $100 \mu \mathrm{L}$ of sample) or sTNFRII (minimum $20 \mu \mathrm{L}$ of sample) using commercially available human ELISA kits (DRA00B and DRT200, R\&D Systems). For statistical purposes, a value of $1 / 2$ the lowest level of detection (LLOD) was used for any value that was below the level of detection (IL1-Ra: $3.1 \mathrm{pg} / \mathrm{mL}$ and sTNFRII: $0.3 \mathrm{pg} / \mathrm{mL}$ ). The reported mean intra- and inter-assay coefficients of variation for IL-1Ra are 5.3\% and $8.6 \%$, respectively. The reported mean intra- and inter-assay coefficients of variation for sTNFRII are 3.5\% and $4.1 \%$, respectively.

\section{Study groups and nomenclature}

Five groups were created in order to identify the effects of inhibition of IL- 1 and TNF- $\alpha$ on healing time after a simple articular fracture. Group 1 (fracture with no treatment, denoted Fx) acted as a fractured control group, where no treatment of any kind was given post-fracture. Group 2 acted as the vehicle control, with intra-articular delivery of xELP[PBS]. Group 3 received intra-articular injection of the IL-1 receptor antagonist (anakinra) with the $x E L P[I L 1 R a]$ depot. Group 4 received intra-articular injection of soluble TNF receptor II (etanercept) with the $\mathrm{xELP}$ [sTNFRII] depot. Group 5 combined the inhibition of IL-1 and TNF- $\alpha$ by giving IL-1Ra and sTNFRII together, denoted xELP[IL-1Ra+sTNFRII].

\section{Animals}

All animal procedures were performed in accordance with protocols approved by the Duke University Institutional Animal Care and Use Committee (IACUC) and the United States Army Medical Department Medical Research and Materiel Command Animal Care and Use Review Office (USAMRMC ACURO). Male C57BL/6J mice ( $n=77$, Charles River Laboratories, Wilmington, MA, USA) were obtained at 11 weeks of age. Mice were housed until 16 weeks of age. Five groups were then designated, with all groups subjected to a closed articular fracture of the left knee, as described previously (Furman et al., 2007). Groups 1, 2, and 3 each contained 16 mice, group 4 contained 12 mice, and group 5 contained 14 mice. 16 additional $\mathrm{C} 57 \mathrm{BL} / 6 \mathrm{~J}$ mice were obtained and sacrificed at 4 weeks and 8 weeks to serve as age-matched controls for the biomarker analyses.

\section{Articular fracture protocol}

Closed articular fractures were created using a previously described murine articular fracture model (Furman et al., 
2007). Each mouse was sedated (pentobarbital, IP $60 \mathrm{mg} /$ $\mathrm{kg}$ ) and placed into a custom cradle that positioned the left hind limb at neutral $\left(90^{\circ}\right.$ flexion). This cradle was

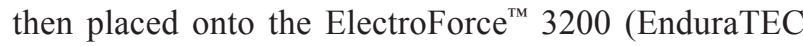
Systems, Minnetonka, MN, USA). A preload of $-10 \mathrm{~N}$ was then applied to the tibia using a custom polished stainlesssteel wedge-shaped indenter. The tibia was then loaded in compression at a rate of $20 \mathrm{~N} / \mathrm{s}$ (55 N maximum) using a $-3.2 \mathrm{~mm}$ displacement limit to create a simple fracture. Groups 2-5 then received their designated treatment immediately after fracture. For intra-articular injections, Hamilton syringes were used with $27 \mathrm{G}$ needles under sterile conditions.

\section{Collection of materials at sacrifice}

Mice from each group were sacrificed at 4 weeks $(n=6-8)$ and 8 weeks $(n=6-8)$ post-fracture. At the time of sacrifice, serum and synovial fluid from each limb were collected from each mouse and stored for use in biomarker analysis, as described previously (Seifer et al., 2008). Both hind limbs from each mouse were harvested and fixed at $90^{\circ}$ flexion in $10 \%$ neutral buffered formalin for $5 \mathrm{~d}$, then transferred to $70 \%$ ethanol.

\section{MicroCT assessment}

A scan of each limb was taken using micro-computed tomography (MicroCT 40, Scanco Medical AG, Bassersdorf, Switzerland) to perform bone morphology analysis. A global threshold procedure enabled the separation of calcified tissues and soft tissues, which allowed for analysis of specific landmarks in the knee. Three regions are of interest when identifying the effects of PTA: the cancellous bone fraction of the femoral condyles, the tibial plateaus, and the metaphyseal region of the tibia. The parameters that were evaluated include bone volume, bone density, cancellous bone fraction (bone volume/ total volume), trabeculae number, trabeculae thickness, and trabeculae spacing. We subtracted the value of the contralateral control limb from the fractured limb to get the resultant change between limbs as a result of fracture for all measured values.

\section{Histological processing of limbs}

Immediately following scanning, hind limbs were prepared for histology. Decalcification of the limbs was done using Cal-Ex Decalcification Solution (Fisher Scientific, Pittsburgh, PA, USA) for 4-5 d. Limbs were then dehydrated, infiltrated, and paraffin-embedded using the Leica ASP300S Tissue Processor (Leica Microsystems, Buffalo Grove, IL, USA).

\section{Articular cartilage assessment}

Articular cartilage pathology was evaluated using histological analysis and semi-quantitative grading. Sequential sections $(8 \mu \mathrm{m})$ of fixed limbs in the coronal plane were obtained and stained using Safranin-O (SigmaAldrich, St. Louis, MO, USA), Harris Hematoxylin (Poly Scientific, Bay Shore, NY, USA), and Fast Green (Electron Microscopy Sciences, Hatfield, PA, USA). A modified Mankin histological scoring system was used by three blinded graders to evaluate cartilage pathology and degenerative changes (Furman et al., 2007). The lateral femur, lateral tibia, medial femur, and medial tibia were each graded separately. Parameters examined include subchondral bone thickness, articular cartilage structure, tidemark duplication, Safranin-O staining, fibrocartilage, chondrocyte clones, and hypertrophic chondrocytes. A total modified Mankin score representing the state of the joint cartilage was obtained by summing the individual location scores with a maximum score of 120 possible for each joint.

\section{Synovial inflammation assessment}

Synovial pathology was examined using histological analysis and semi-quantitative grading. Sequential sections of fixed limbs were stained using Harris Hematoxylin and Eosin (Poly Scientific). A modified synovial histological scoring system was used by three blinded graders to evaluate synovitis in each joint (Lewis et al., 2013). The synovial insertion of the lateral femur, lateral tibia, medial femur, and medial tibia were each graded separately. Parameters examined include synovial lining thickness and cellular density in the synovial stroma. A total modified synovitis score per side was obtained by summing the individual location scores on the lateral side and the medial side with a maximum score of 12 possible for each side of the joint.

\section{Serum and synovial fluid biomarker assays}

Serum and synovial fluid collected at sacrifice were used to perform biomarker analyses. An age-matched control group, which received no fractures or treatments, served as a biomarker control group. Serum ELISAs for interleukin 6 (IL-6), macrophage-derived chemokine (MDC), thymus and activation-regulated chemokine (TARC), matrix metalloproteinase-3 (MMP-3) (R\&D Systems), cartilage oligomeric matrix protein (COMP) (MD Bioproducts, St. Paul, MN, USA), hyaluronic acid (HA) (Corgenix, Broomfield, CO, USA), transforming growth factor- $\beta_{1}$ (TGF- $\beta_{1}$ ) (BioLegend, San Diego, CA, USA) and synovial fluid assays for IL-6 (R\&D Systems) and COMP were performed according to the manufacturers' instructions. For the purposes of statistical analyses, in each of the assays, $1 / 2$ the lower limit of detection (LLOD), or minimum detectable dose, was substituted for any value that was determined to be below the limit of detection. Serum and synovial fluid levels of mouse IL-6 were quantified by sandwich ELISA utilizing $50 \mu \mathrm{L}$ of undiluted serum or synovial fluid diluted $1: 5$, requiring $10 \mu \mathrm{L}$ of sample. The reported mean intra- and inter-assay coefficients of variation of the assay were $4.7 \%$ and $7.5 \%$, respectively, and the minimum detectable dose was reported to be $1.6 \mathrm{pg} /$ $\mathrm{mL}$. For serum IL-6, $38 \%$ of the samples (34 of 90) were below the level of detection and for synovial fluid, $61 \%$ of the samples were below the level of detection. Serum levels of MDC were quantified by sandwich ELISA utilizing $20 \mu \mathrm{L}$ of sample in a 3 -fold dilution. The reported mean intra- and inter-assay coefficients of variation of the assay were $5.4 \%$ and $7.2 \%$, respectively, and the minimum detectable dose was reported to be $1.2 \mathrm{pg} / \mathrm{mL}$. Values were obtained for all samples analyzed. Serum levels of 
TARC were quantified by sandwich ELISA utilizing $50 \mu \mathrm{L}$ of undiluted sample. The reported mean intra- and interassay coefficients of variation of the assay were $3.4 \%$ and $6.7 \%$, respectively, and the minimum detectable dose was reported to be $5 \mathrm{pg} / \mathrm{mL}$. Values were obtained for all samples analyzed. Serum levels of MMP-3 were assessed by sandwich ELISA at a dilution of 1:20. The reported mean intra- and inter-assay coefficients of variation of the assay were $3.0 \%$ and $7.6 \%$, respectively, and the minimum detectable dose was reported to be $0.019 \mathrm{ng} / \mathrm{mL}$. Values were obtained for all samples analyzed. Serum and synovial fluid levels of mouse COMP were quantified by competitive ELISA requiring a 1:10 dilution of serum and a 1:5 dilution of synovial fluid. The reported mean intra- and inter-assay coefficients of variation of the assay were $9.4 \%$ and $6.5 \%$, respectively, and the minimum detectable dose was reported to be $0.2 \mathrm{U} / \mathrm{L}$. Values were obtained for all samples analyzed. Serum levels of hyaluronic acid were quantified by sandwich ELISA utilizing $12 \mu \mathrm{L}$ of sample. Information on the coefficients of variation of the assay were not provided by the manufacturer, however, three controls (low, moderate, and high) were provided and all ran within the acceptable range. Values were obtained for all samples analyzed. Two different sandwich ELISAs were employed for the determination of Free Active TGF- $\beta_{1}$ and Total TGF- $\beta_{1}$. Samples were run undiluted for Free Active TGF- $\beta_{1}$ and diluted 1000 -fold for Total TGF- $\beta_{1}$, as recommended by the manufacturer. The minimal detectable concentration of Free Active TGF- $\beta$, was reported as $2.3 \mathrm{pg} / \mathrm{mL}$ and $3.5 \mathrm{pg} / \mathrm{mL}$ for Total TGF- $\beta_{1}$. The intra- and inter-assay CVs were $9.1 \%$ and $8.0 \%$, respectively, for Free Active TGF- $\beta_{1}$ and $3.6 \%$ and $6.6 \%$, respectively, for Total TGF- $\beta_{1}$. Values were obtained for all samples.

\section{Statistical analysis}

All analyses were conducted using STATISTICA (v.7, StatSoft, Inc., Tulsa, OK, USA) with significance reported at the $95 \%$ confidence level. Data were examined using repeated measures to examine differences between the control and experimental limb, along with the reduction of PTA symptoms among the different treatment types and times. For data that were normally distributed, parametric analysis was performed; otherwise, non-parametric analysis was performed.

For the microCT analysis, a multifactorial ANOVA was performed with the contralateral control limb and fractured limb as the repeated measure. Treatment groups and time points served as the dependent variables. A Tukey honestly significant difference (HSD) post-hoc test was performed to determine significance between treatment groups and time points.

For the Mankin and synovitis scores, non-parametric analysis was performed. A Wilcoxon matched pairs test was used to report significance between the contralateral control limb and the fractured limb. A Kruskal-Wallis ANOVA was used to compare individual groups against each other at each time point. A Mann-Whitney U test was performed to determine statistical differences within a group at 4 and 8 weeks.

For the biomarker data, non-parametric analysis was performed. A Kruskal-Wallis ANOVA was used to compare individual groups at each time point, and a Mann-Whitney $\mathrm{U}$ test was performed to determine statistical differences within groups at 4 and 8 weeks.

\section{Results}

Release of drug from xELP in vitro showed sustained release of IL-1Ra and sTNFRII over 7 days

Drugs were loaded into cross-linked ELP depots (xELP) by rehydrating the lyophilized XELP in drug-containing solutions (Fig. 1a). Under these conditions and for this ELP sequence, the temperature-induced transition is retained at $37^{\circ} \mathrm{C}$ and is observed as a change in opacity of the drugloaded xELP construct (Fig. 1b). In vitro experiments in $10 \%$ serum-containing media were conducted in order to determine the drug release profile from the cross-linked xELP depots. The $10 \%$ serum-containing media and $37^{\circ} \mathrm{C}$ culture condition was used to mimic the conditions present in synovial fluid. Over a period of $7 \mathrm{~d}$, the release profiles of both xELP[IL-1Ra] (Fig. 1c) and xELP[sTNFRII] (Fig. 1d) were similar, with a release of drug that plateaued at day 2 and day 3 , respectively. With xELP depot formation at $37^{\circ} \mathrm{C}$, the majority of the drug was encapsulated. However, there was an initial release of drug from the xELP depot that likely reflects drug that was not fully encapsulated by the transitioning xELP. The in vitro release profiles of both IL-1Ra and sTNFRII indicated that the xELP depots successfully released these drugs over an extended 7-day period.

\section{Release of drug from XELP in vivo showed sustained release of IL-1Ra and sTNFRII over 5 days}

Serial blood draws were taken from the mice throughout the study and processed for serum collection; due to the small volume, mice from each treatment group at each time point were pooled to determine the serum levels of human IL-1Ra (hIL-1Ra) and sTNFRII (hsTNFRII) in the mice following intra-articular drug delivery. As expected, the levels of hIL-1Ra were undetectable in the fracture only with no treatment $(\mathrm{Fx})$ group, and in the group receiving depots loaded with PBS only (xELP[PBS]). The serum of the $x E L P[I L-1 R a]$ group had measurable levels of hIL-1Ra on day 1 of $\sim 5 \mathrm{ng} / \mathrm{mL}$, and still had detectable levels at day 5 (Fig. 2a). In the xELP[IL-1Ra+sTNFRII] group, there was a detectable serum level of hIL-1Ra of over $30 \mathrm{ng} /$ $\mathrm{mL}$ on day 1 , which then fell to an undetectable level by day 5. As expected, levels of hsTNFRII were undetectable in the Fx group and the xELP[PBS] group (Fig. 2b). The $x$ ELP[sTNFRII] group had measurable serum levels of hsTNFRII of over $1,100 \mathrm{ng} / \mathrm{mL}$ on day 1 , which fell to $300 \mathrm{ng} / \mathrm{mL}$ by day 5 and was undetectable by day 14 . In the combination therapy, serum hsTNFRII was greater than $550 \mathrm{ng} / \mathrm{mL}$ on day 1 , dropped to $\sim 450 \mathrm{ng} / \mathrm{mL}$ on day 5 , and was undetectable by day 14 . The in vivo release profiles indicated that the single drug therapies remained in the serum for at least $5 \mathrm{~d}$ after an intra-articular injection, and the combination therapy drugs remained in the serum for 1-5 d after an intra-articular injection, demonstrating that the xELP depots successfully released the drugs over an extended period of $5 \mathrm{~d}$. 

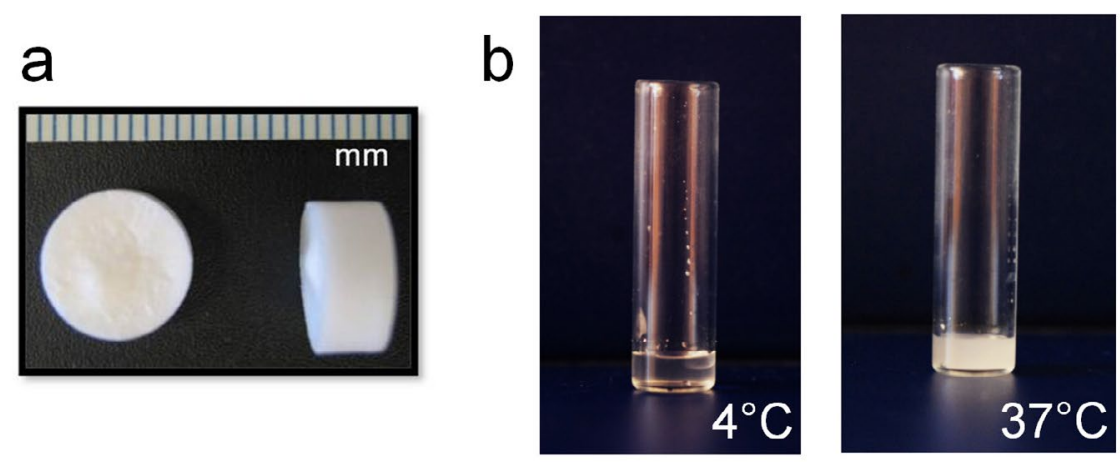

C

d
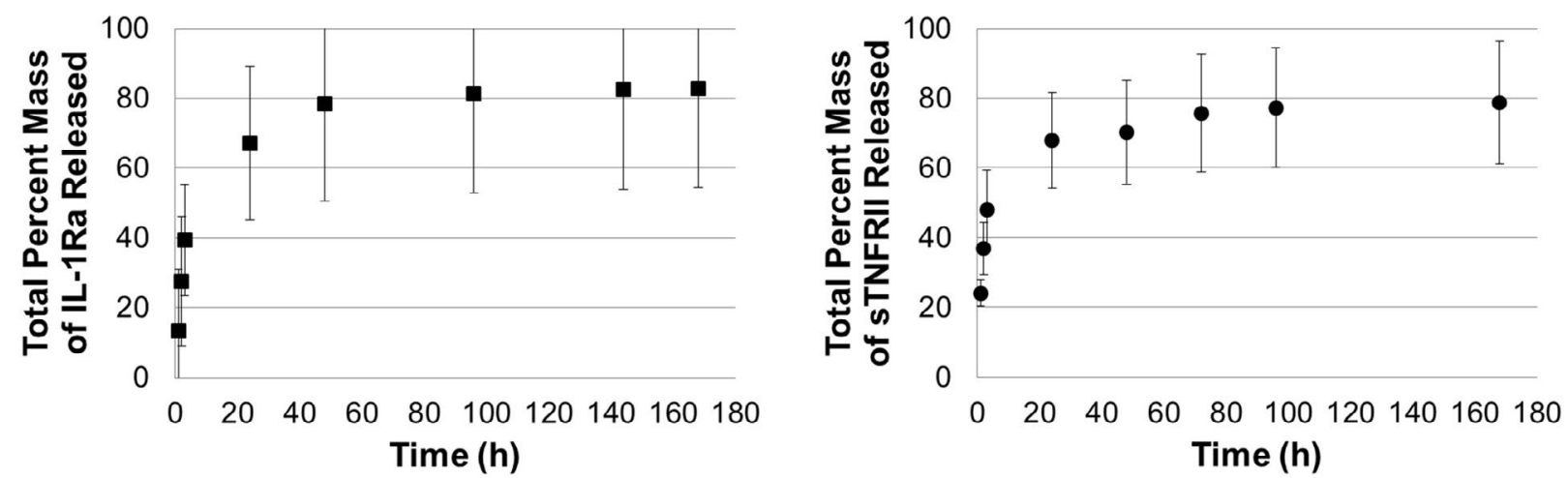

Fig. 1. Results of in vitro drug release studies. (a) Close-up image of lyophilized xELP constructs. (b) Drug rehydrated xELP constructs at $4{ }^{\circ} \mathrm{C}$ (left) and at $37^{\circ} \mathrm{C}$ (right). Change in opacity of the xELP at the transition-induced temperature of $37{ }^{\circ} \mathrm{C}$ is seen by comparing the left and right pictures. (c) Drug release of IL-1Ra from xELP in $10 \%$ serum-containing medium over $180 \mathrm{~h}$. Mean \pm standard deviation reported $(n=4)$. (d) Drug release of sTNFRII from xELP in $10 \%$ serum-containing medium over $180 \mathrm{~h}$. Mean \pm standard deviation reported $(n=4)$.

a

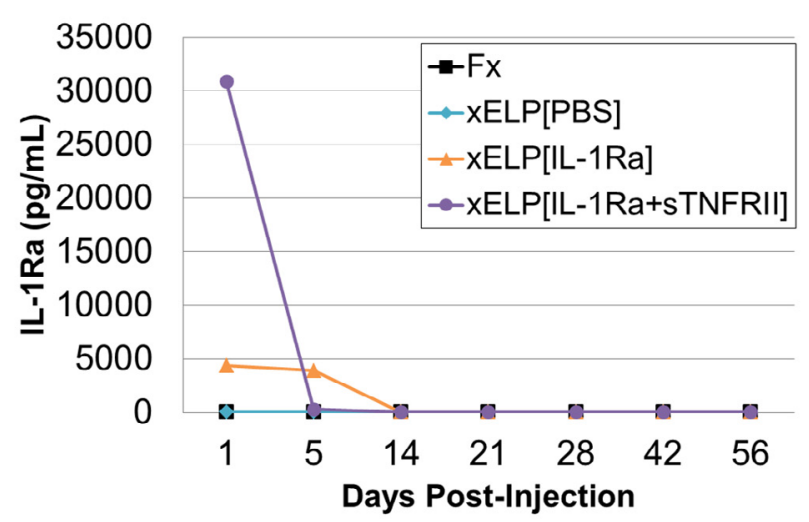

b

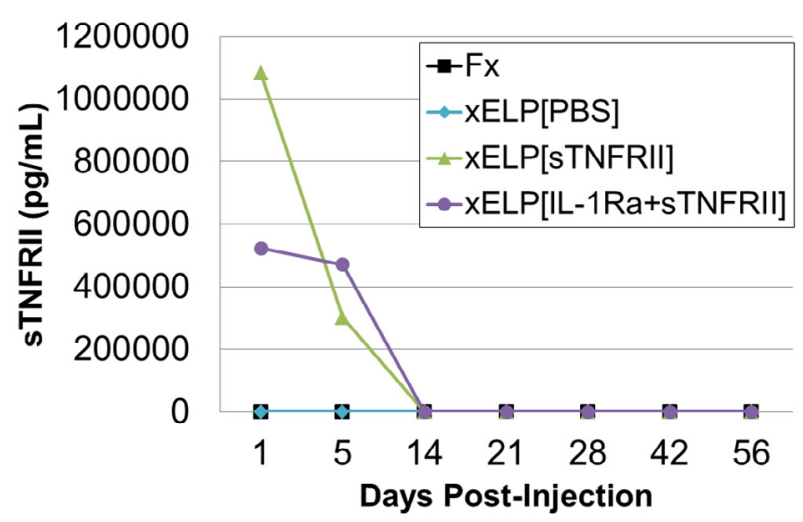

Fig. 2. Results of in vivo drug release studies. (a) Drug release of IL-1Ra from xELP in mouse serum as measured by ELISA. Fx and xELP[PBS] were run as background controls for ELISA. Data are mean of samples in triplicate ( $n=6$-11 per data point). (b) Drug release of sTNFRII from XELP in mouse serum as measured by ELISA. Fx and $\mathrm{xELP}[\mathrm{PBS}]$ were run as background controls for ELISA. Data are mean of samples in triplicate $(n=6-11$ per data point $)$.

\section{Histological assessment of joint tissues showed that $x E L P[I L-1 R a]$ reduced articular cartilage degeneration}

Articular cartilage degeneration was quantified from histological sections using the Mankin score of the contralateral control limb and the fractured limb for each mouse. At 4 weeks (Fig. 3a), there was no significant increase in Mankin scores between the fractured limb and the contralateral control limb in the fracture only with no treatment $(\mathrm{Fx})$ group $(p=0.09)$, the $\mathrm{xELP}[\mathrm{PBS}]$ group $(p=0.16)$, the xELP[IL-1Ra] group $(p=0.67)$ or the xELP[IL-1Ra+sTNFRII] group $(p=0.18)$; however, in the $\mathrm{xELP}$ [sTNFRII] group at 4 weeks, there was a significant increase in Mankin score between the fractured limb and the contralateral control limb $(p=0.04)$. By 8 weeks (Fig. $3 b)$ there were significantly greater Mankin scores in 
a

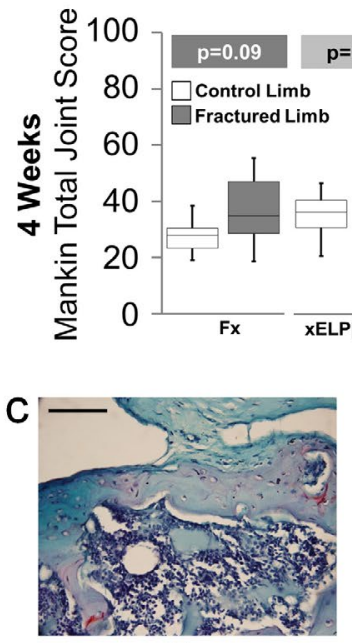

Fx
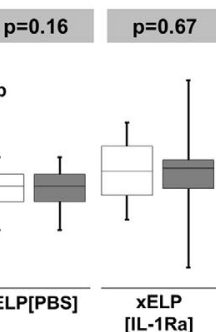

XELP
[sTNFRII]

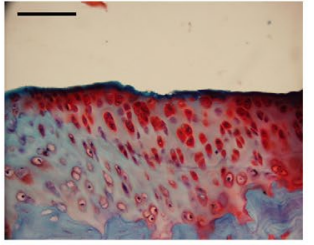

$x E L P[P B S]$ b
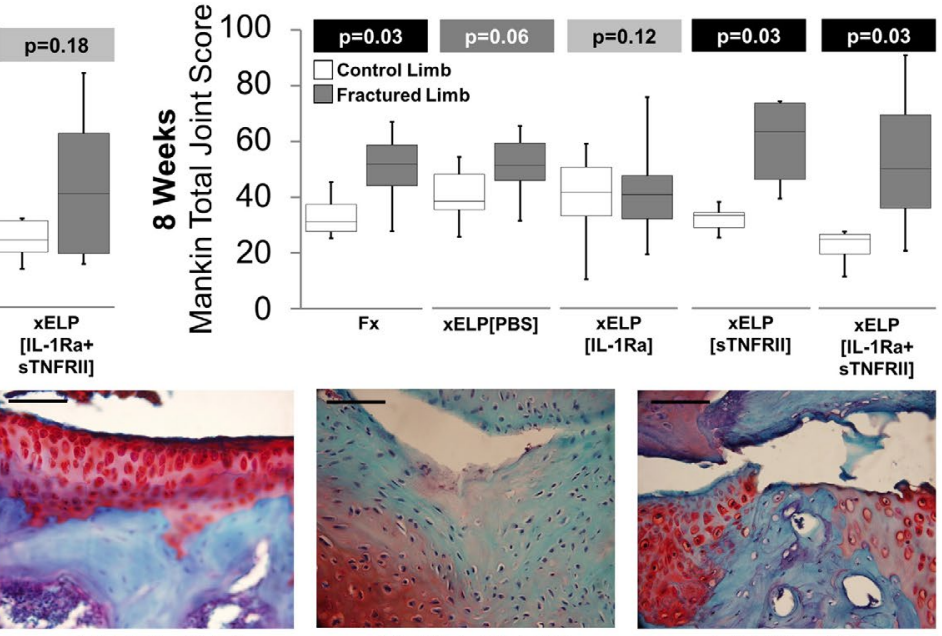

xELP[IL-1Ra]

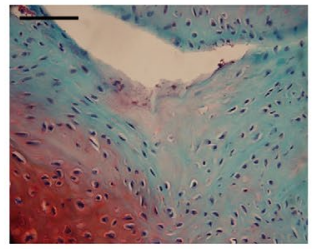

xELP[STNFRII]

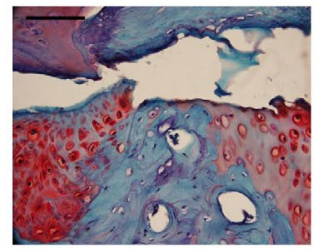

xELP[IL-1Ra +sTNFRII]

Fig. 3. Assessment of articular cartilage degeneration. (a) Modified Mankin total joint score for limbs at 4 weeks. $p$ values denote significance between control and fractured limb using Wilcoxon Matched Pairs test. Median values and $25^{\text {th }}-75^{\text {th }}$ quartile range reported ( $n=6-8$ per group). (b) Modified Mankin total joint score for limbs at 8 weeks. $p$ values denote significance between control and fractured limb using Wilcoxon Matched Pairs test. Median values and $25^{\text {th }}-75^{\text {th }}$ quartile range reported ( $n=6-8$ per group). (c) Representative histological pictures of articular cartilage on the lateral tibial plateau taken at $40 \times$ magnification for each group with Safranin-O/Fast Green staining at 8 weeks. Scale bar indicates $5 \mu \mathrm{m}$.

a

b

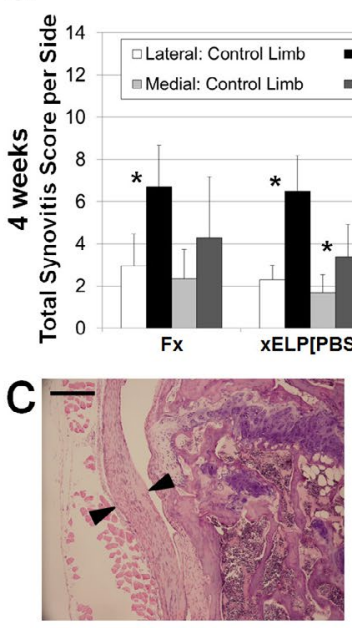

Fx

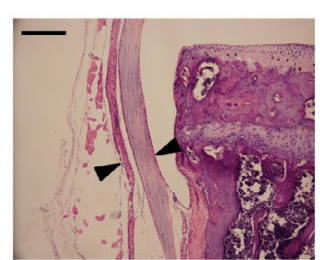

xELP[PBS]
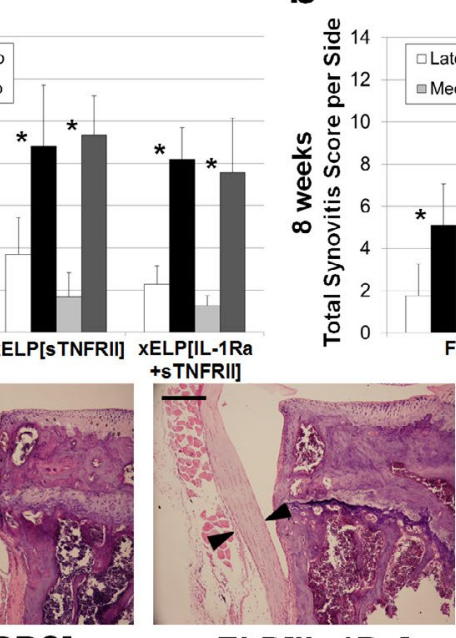

xELP[IL-1Ra]

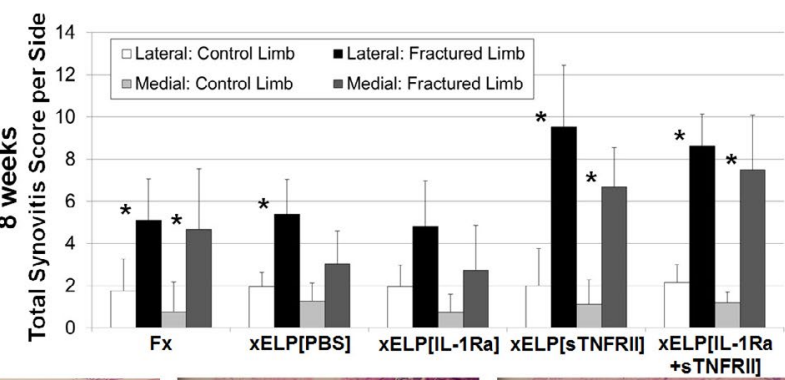

(5)

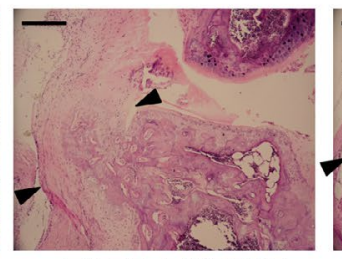

xELP[STNFRII]

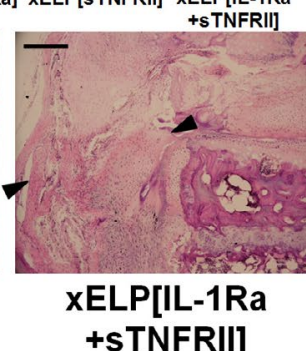

Fig. 4. Assessment of synovial inflammation. (a) Modified Krenn joint score for medial and lateral sides of each limb at 4 weeks. * denotes $p<0.05$ between control and fractured limb using Wilcoxon Matched Pairs test. Mean \pm standard deviation reported ( $n=5-8$ per group). (b) Modified Krenn joint score for medial and lateral sides of each limb at 8 weeks. * denotes $p<0.05$ between control and fractured limb using Wilcoxon Matched Pairs test. Mean \pm standard deviation reported ( $n=5-8$ per group). (c) Representative histological pictures of synovium (black arrows) in the lateral tibial plateau quadrant of knee joints at 8 weeks using Hematoxylin and Eosin stained sections. Scale bar indicates $10 \mu \mathrm{m}$.

the fractured limb compared to the contralateral control limb for the Fx group $(p=0.03)$, the xELP[sTNFRII] group $(p=0.03)$, and the xELP[IL-1Ra+sTNFRII] group $(p=0.03)$. There was also a trend of increased Mankin scores in the fractured limb of the xELP[PBS] group $(p=0.06)$ at 8 weeks. In contrast, there was no increase in Mankin score in the fracture limb of the xELP[IL-1Ra] group ( $p=0.12)$ at 8 weeks Histology of the lateral tibia at 8 weeks showed a severe loss of proteoglycan staining and subsequent fibrocartilage healing in the fractured limb of the Fx group (Fig. 3c). In the xELP[PBS] group, there was evidence of surface fibrillation in the articular cartilage, while in the xELP[IL-1Ra] group, the fractured limb demonstrated only minimal structural changes. In 
a

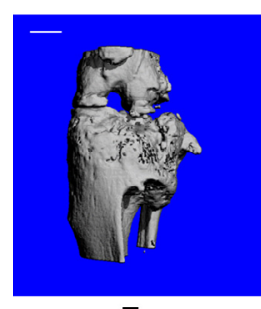

Fx

b

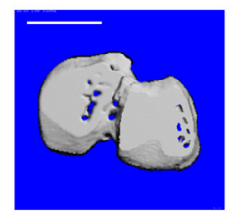

Fx-Control

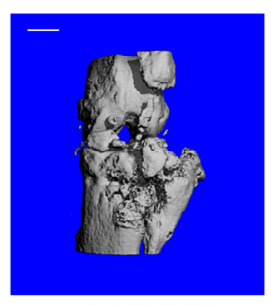

$x E L P[P B S]$

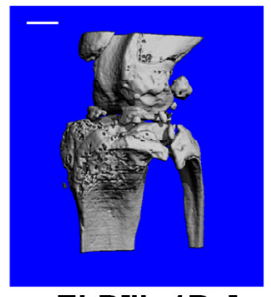

XELP[IL-1Ra]

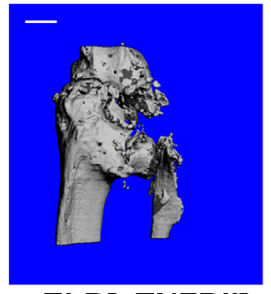

xELP[STNFRII]

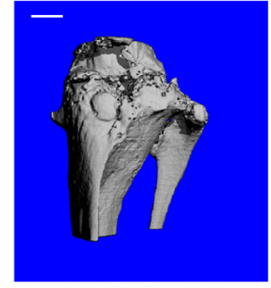

XELP[IL-1Ra +STNFRII]

C

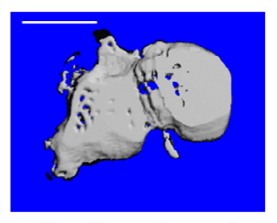

Fx-Fractured

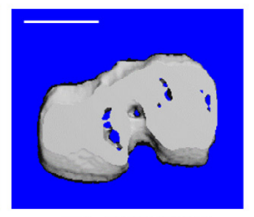

$\mathrm{xELP}[\mathrm{PBS}]$

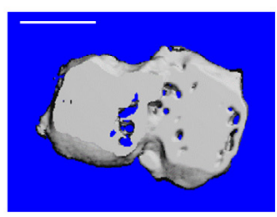

XELP[IL-1Ra]

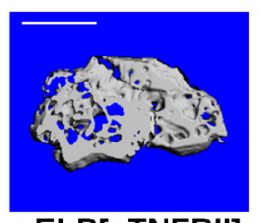

$x E L P[s T N F R I I] \quad x E L P[I L-1 R a+s T N F R I I]$

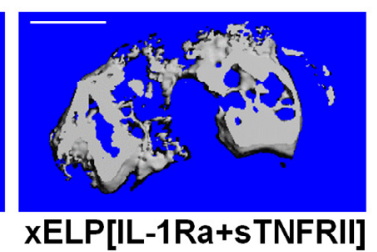

d

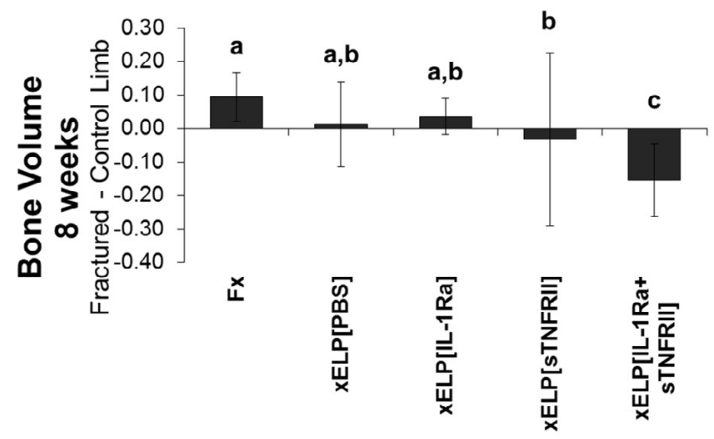

f

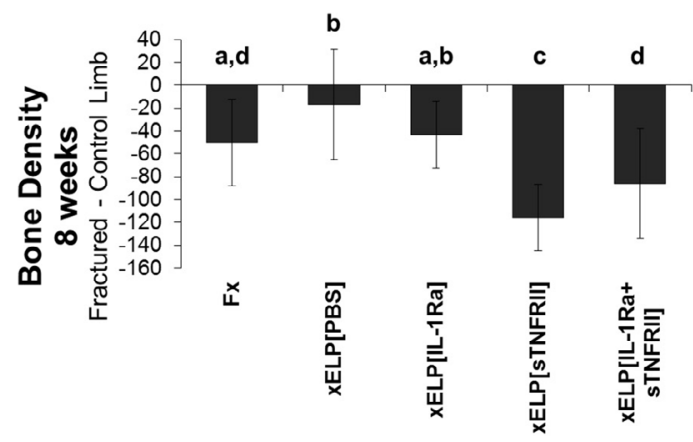

Fig. 5. Assessment of bone morphological changes. (a) Representative microCT images of the fractured limb from each group at 8 weeks. Fractures are present in each image in the lateral tibial plateau. Scale bar indicates $1 \mathrm{~mm}$. (b) Representative microCT images of the tibial plateau of a control limb (first picture) and fractured limbs (pictures 2-6) from each group at 8 weeks. Scale bar indicates $1 \mathrm{~mm}$. (c) Bone volume data shown at 4 weeks for each group. Tukey HSD post-hoc test performed; groups that do not share letters are significantly different from each other $(p<0.05)$. Mean \pm standard deviation reported ( $n=5-8$ per group). (d) Bone volume data shown at 8 weeks for each group. Tukey HSD post-hoc test performed; groups that do not share letters are significantly different from each other $(p<0.05)$. Mean \pm standard deviation reported ( $n=5-8$ per group). (e) Bone density data shown at 4 weeks for each group. Tukey HSD post-hoc test performed; groups that do not share letters are significantly different from each other $(p<0.05)$. Mean \pm standard deviation reported ( $n=5-8$ per group). (f) Bone density data shown at 8 weeks for each group. Tukey HSD post-hoc test performed; groups that do not share letters are significantly different from each other $(p<0.05)$. Mean \pm standard deviation reported $(n=5-8$ per group). 
a

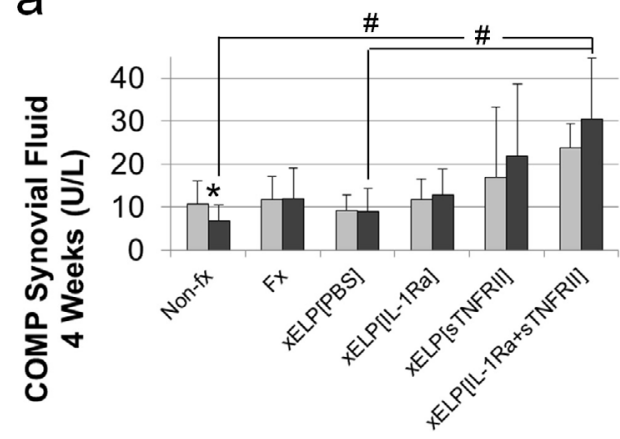

C

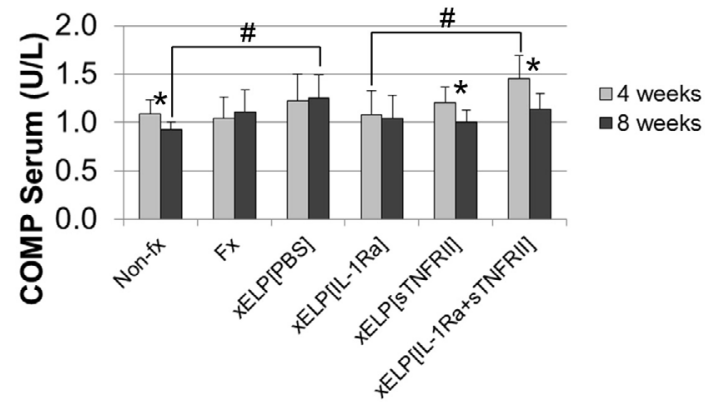

b

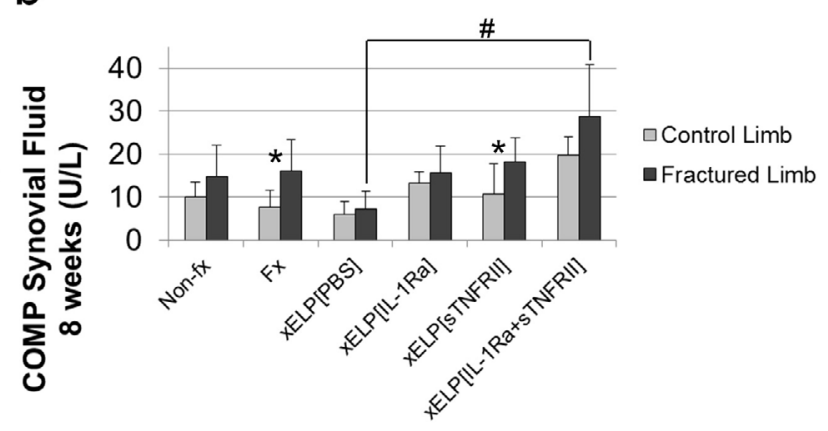

d

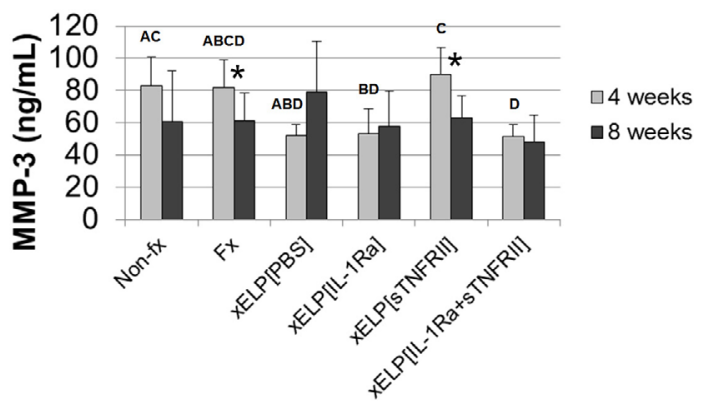

Fig. 6. Assessment of serum and synovial fluid biomarkers. (a) Levels of cartilage oligomeric matrix protein (COMP) in synovial fluid in the limbs at 4 weeks. Mean \pm standard deviation reported $(n=5-8$ per group). \# denotes $p<0.05$ between groups using Kruskal-Wallis ANOVA. * denotes $\mathrm{p}<0.05$ between fractured and control limb using Wilcoxon Matched Pairs test. (b) Levels of COMP in synovial fluid in the limbs at 8 weeks. Mean \pm standard deviation reported ( $n=5-8$ per group). \# denotes $p<0.05$ between groups using Kruskal-Wallis ANOVA. * denotes $p<0.05$ between fractured and control limb using Wilcoxon Matched Pairs test. (c) Levels of COMP in serum for each group at 4 and 8 weeks. Mean \pm standard deviation reported ( $n=5-8$ per group). \# denotes $p<0.05$ between groups using KruskalWallis ANOVA. * denotes $p<0.05$ between 4 and 8 weeks using Kruskal-Wallis ANOVA test. (d) Levels of matrix metalloproteinase-3 (MMP-3) in serum for each group at 4 and 8 weeks. Mean \pm standard deviation reported $(n=5-8$ per group). ${ }^{*}$ denotes $p<0.05$ between 4 and 8 weeks using Kruskal-Wallis ANOVA. Groups that do not share letters are significantly different $(p<0.05)$ at 4 weeks by Kruskal-Wallis ANOVA.

contrast, the $\mathrm{xELP}[\mathrm{sTNFRII}]$ limb showed an outgrowth of fibrocartilage at the site of fracture which made it difficult to distinguish the original margins of the articular cartilage surface. A similar phenomenon was present in the $x E L P[I L-1 R a+s T N F R I I]$ limb, where there was little evidence of fracture healing save for some strands of fibrocartilage seen near the boundary of the growth plate.

\section{Histological assessment showed that xELP[IL-1Ra] reduced the severity of synovitis}

The degree of synovial inflammation was assessed from histological sections using a synovitis score of the contralateral control limb and the fractured limb for each mouse. At 4 weeks (Fig. 4a), all 5 groups showed a significant difference between the contralateral control limb and the fractured limb on the lateral side of the joint, where the fracture was typically located. On the medial side of the joint, the fracture only with no treatment (Fx) group was the only group that did not show a significant increase in synovitis between the fractured and contralateral control limb $(p=0.21)$; the other 4 groups had increased synovitis in the fractured limb $(p<0.05)$. However, at 8 weeks (Fig. 4b), both lateral and medial sides of the joint showed increased synovitis in the fractured limb for the
Fx group $(p=0.04, p=0.01)$, the XELP[sTNFRII] group $(p=0.03, p=0.03)$, and the xELP[IL-1Ra+sTNFRII] group $(p=0.03, p=0.03)$. From the representative histological pictures of the medial tibia taken at 8 weeks (Fig. 4c), the fractured limb in the Fx group demonstrated increased inflammation in the synovial attachment to the tibial plateau. The xELP[PBS] group and the xELP[IL-1Ra] group had minimal synovial inflammation and did not show a significant difference between limbs in total synovitis score on the medial side. Both the xELP[sTNFRII] group and the xELP[IL-1Ra+sTNFRII] group showed inflamed synovium, with dramatically increased cellular infiltration. From the synovitis grading and images, we concluded that both the xELP[PBS] and xELP[IL-1Ra] treatments provided a reduction in synovial inflammation on the medial side, and that treatment with xELP[IL-1Ra] also provided a benefit on the lateral side of the joint.

\section{MicroCT assessment of bone properties showed a trend towards increased bone volume, but decreased bone density at 8 weeks}

Bone morphological changes were assessed using microcomputed tomography (microCT) in the contralateral control and fractured limbs. Fractures were confirmed 
Table 1. Biomarker levels in mouse serum and synovial fluid at 4 and 8 weeks.

\begin{tabular}{|c|c|c|c|c|c|c|c|}
\hline SERUM* 4 weeks & Non-fx & $\mathbf{F x}$ & ELP-PBS & ELP-IL-1Ra & ELP-sTNFRII & $\begin{array}{c}\text { ELP-IL- } \\
\text { 1Ra+sTNFRII }\end{array}$ & $\underset{p \text { (groups) }}{\text { Kruskal-Wallis }}$ \\
\hline $\mathrm{HA}(\mathrm{pg} / \mathrm{mL})$ & $3.50 \mathrm{e} 5 \pm 0.14 \mathrm{e} 5$ & $3.31 \mathrm{e} 5 \pm 0.88 \mathrm{e} 5$ & $3.56 \mathrm{e} 5 \pm 0.12 \mathrm{e} 5$ & $4.18 \mathrm{e} 5 \pm 0.14 \mathrm{e} 5$ & $3.35 \mathrm{e} 5 \pm 0.89 \mathrm{e} 5$ & $2.89 \mathrm{e} 5 \pm 0.49 \mathrm{e} 5$ & none \\
\hline IL-6 (pg/mL) & $117.00 \pm 91.51^{A}$ & $34.29 \pm 34.55^{\mathrm{ABC}}$ & $8.81 \pm 13.96^{\mathrm{BC}}$ & $16.03 \pm 14.58^{\mathrm{ABC}}$ & $28.05 \pm 22.47^{\mathrm{ABC}}$ & $2.73 \pm 5.59^{\mathrm{BC}}$ & $p<0.002$ \\
\hline $\mathrm{MDC}(\mathrm{pg} / \mathrm{mL})$ & $224.73 \pm 29.78$ & $212.23 \pm 43.46$ & $207.50 \pm 12.95$ & $213.46 \pm 22.93$ & $189.98 \pm 12.91$ & $226.89 \pm 36.15$ & none \\
\hline TARC $(\mathrm{pg} / \mathrm{mL})$ & $101.60 \pm 14.39^{\mathrm{AB}}$ & $82.38 \pm 17.91^{\AA}$ & $102.65 \pm 15.50^{\mathrm{AB}}$ & $93.00 \pm 8.42^{\mathrm{AB}}$ & $93.72 \pm 7.93^{\mathrm{AB}}$ & $108.06 \pm 12.46^{\mathrm{B}}$ & $p=0.0095$ \\
\hline TGF- $\beta_{1}$ Free Active (pg/mL) & $181.34 \pm 63.76$ & $193.81 \pm 52.03$ & $143.23 \pm 33.98$ & $157.56 \pm 38.74$ & $196.02 \pm 33.48$ & $184.23 \pm 44.27$ & none \\
\hline TGF- $\beta_{1}$ Total $(\mathrm{pg} / \mathrm{mL})$ & $62692.25 \pm 9531.97^{\mathrm{AB}}$ & $71449.75 \pm 10323.00^{\mathrm{AB}}$ & $56167.29 \pm 5723.62^{\mathrm{A}}$ & $64542.13 \pm 6538.26^{\mathrm{AB}}$ & $76986.33 \pm 15707.00^{\mathrm{B}}$ & $63363.00 \pm 8615.71^{\mathrm{AB}}$ & $p=0.0230$ \\
\hline TGF- $\beta_{1}$ Free Active/Total & $0.0029 \pm 0.0010$ & $0.0027 \pm 0.0006$ & $0.0025 \pm 0.006$ & $0.0025 \pm 0.0007$ & $0.0028 \pm 0.0012$ & $0.0030 \pm 0.0009$ & none \\
\hline SERUM $* 8$ weeks & Non-fx & $\mathbf{F x}$ & ELP-PBS & ELP-IL-1Ra & ELP-sTNFRII & $\begin{array}{c}\text { ELP-IL- } \\
\text { 1Ra+sTNFRII }\end{array}$ & $\underset{p \text { (groups) } \dagger}{\text { Kruskal-Wallis }}$ \\
\hline $\mathrm{HA}(\mathrm{pg} / \mathrm{mL})$ & $4.41 \mathrm{e} 5 \pm 0.11 \mathrm{e} 5$ & $4.87 \mathrm{e} 5 \pm 0.32 \mathrm{e} 5$ & $4.29 \mathrm{e} 5 \pm 0.14 \mathrm{e} 5$ & $3.71 \mathrm{e} 5 \pm 0.11 \mathrm{e} 5$ & $3.15 \mathrm{e} 5 \pm 0.46 \mathrm{e} 5$ & $3.81 \mathrm{e} 5 \pm 0.15 \mathrm{e} 5$ & none \\
\hline IL-6 (pg/mL) & $79.70 \pm 95.10$ & $63.52 \pm 88.89$ & $40.66 \pm 52.27$ & $7.15 \pm 11.43$ & $10.08 \pm 11.51$ & $2.09 \pm 3.59$ & none \\
\hline MDC (pg/mL) & $193.27 \pm 21.60$ & $213.38 \pm 16.79$ & $204.06 \pm 44.83$ & $193.89 \pm 28.03$ & $206.93 \pm 45.17$ & $232.76 \pm 26.58$ & none \\
\hline TARC $(\mathrm{pg} / \mathrm{mL})$ & $101.39 \pm 15.61$ & $101.59 \pm 8.18$ & $104.41 \pm 19.38$ & $104.08 \pm 16.89$ & $95.10 \pm 24.30$ & $106.88 \pm 12.03$ & none \\
\hline TGF- $\beta_{1}$ Free Active $(\mathrm{pg} / \mathrm{mL})$ & $198.20 \pm 64.79^{\mathrm{AB}}$ & $175.55 \pm 17.24^{\mathrm{AB}}$ & $113.72 \pm 31.17^{\mathrm{A}}$ & $161.51 \pm 64.68^{\mathrm{AB}}$ & $174.44 \pm 52.46^{\mathrm{AB}}$ & $256.71 \pm 124.00^{\mathrm{B}}$ & $p=0.0086$ \\
\hline TGF- $\beta_{1}$ Total $(\mathrm{pg} / \mathrm{mL})$ & $60755.63 \pm 14857.95^{\mathrm{ABC}}$ & $72337.88 \pm 7516.89^{\mathrm{BC}}$ & $51357.75 \pm 5738.49^{\mathrm{A}}$ & $59918.53 \pm 9272.15^{\mathrm{ABC}}$ & $67391.83 \pm 8336.70^{\mathrm{ABC}}$ & $72954.14 \pm 5864.54^{\mathrm{BC}}$ & $p<0.005$ \\
\hline TGF- $\beta_{1}$ Free Active/Total & $0.0034 \pm 0.0013$ & $0.0024 \pm 0.0040$ & $0.0023 \pm 0.0007$ & $0.0027 \pm 0.0010$ & $0.0026 \pm 0.0008$ & $0.0035 \pm 0.0017$ & none \\
\hline SYNOVIAL FLUID $* 4$ weeks & Non-fx & $\mathbf{F x}$ & ELP-PBS & ELP-IL-1Ra & ELP-sTNFRII & $\begin{array}{c}\text { ELP-IL- } \\
\text { 1Ra+sTNFRII }\end{array}$ & $\underset{p \text { (groups) }}{\text { Kruskal-Wallis }}$ \\
\hline IL-6 R (pg/mL) & $3.29 \pm 9.08$ & $7.91 \pm 14.55$ & $0.08 \pm 0.00$ & $0.08 \pm 0.00$ & $6.97 \pm 16.87$ & $0.08 \pm 0.00$ & none \\
\hline IL-6 L $(\mathrm{pg} / \mathrm{mL})$ & $9.49 \pm 18.45$ & $8.41 \pm 15.43$ & $2.43 \pm 4.38$ & $0.08 \pm 0.00$ & $3.54 \pm 8.47$ & $0.08 \pm 0.00$ & none \\
\hline SYNOVIAL FLUID* 8 weeks & Non-fx & $\mathbf{F x}$ & ELP-PBS & ELP-IL-1Ra & ELP-sTNFRII & $\underset{\text { 1Ra+sTNFRII }}{\text { ELP-IL- }}$ & $\underset{p \text { (groups) } \dagger}{\text { Kruskal-Wallis }}$ \\
\hline IL-6 R (pg/mL) & $3.15 \pm 8.69$ & $8.09 \pm 14.85$ & $1.36 \pm 3.62$ & $0.08 \pm 0.00$ & $7.27 \pm 11.14$ & $0.08 \pm 0.00$ & none \\
\hline IL-6 L (pg/mL) & $7.10 \pm 13.24$ & $4.83 \pm 9.19$ & $2.76 \pm 5.19$ & $1.25 \pm 3.30$ & $22.33 \pm 18.07$ & $0.08 \pm 0.00$ & none \\
\hline
\end{tabular}

*Data are presented as mean \pm standard deviation ( $n=5-8$ per group).

$\dagger$ Groups with different letters are significant from each other as indicated by the Kruskal-Wallis $p$ value.

using microCT images of the entire knee joint (Fig. 5a). In the epiphysis of the tibial plateau, which included the site of articular fracture, morphologic parameters were quantified in the fractured limb and normalized to the contralateral control limb. Representative images of each group showed the effects of the fracture on bone architecture in the tibial plateau (Fig. 5b). At 4 weeks post-fracture (Fig. $5 \mathrm{c}$ ), most treatment groups demonstrated a decrease in bone volume. However, the xELP[sTNFRII] group had a decrease in bone volume that was significant compared to the fracture only with no treatment (Fx) group $(p<0.05)$, and the xELP[IL-1Ra+sTNFRII] group had a decrease in bone volume that was significant compared to the other 4 groups $(p<0.05)$. Likewise, at 8 weeks (Fig. $5 \mathrm{~d})$, most treatment groups demonstrated an increase in bone volume. However, the xELP[sTNFRII] had a decrease in bone volume that was significant compared to the Fx group $(p<0.05)$, and the xELP[IL-1Ra+sTNFRII] group had a decrease in bone volume that was significant compared to the other 4 groups $(p<0.05)$.

All groups demonstrated a decrease in bone density in the epiphysis of the tibial plateau at 4 weeks (Fig. 5e) and at 8 weeks (Fig. 5f). The xELP[PBS] group was significantly different than the Fx group $(p<0.05)$, and the $x$ ELP[sTNFRII] group was significantly different compared to the other 4 groups $(p<0.05)$. These results indicated that over 8 weeks, bone density was not increasing as a result of fracture healing. The increase in bone volume that was seen in the Fx, xELP[PBS], and $\mathrm{xELP}[\mathrm{IL}-1 \mathrm{Ra}$ ] groups at 8 weeks did not contribute to an increase in bone density in the same groups at 8 weeks.

\section{Quantification of PTA-related biomarkers}

Synovial fluid COMP levels in the fractured limb were significantly different between the xELP[PBS] and $x E L P[I L-1 R a+s T N F R I I]$ groups at both 4 weeks $(p=0.0103$, Fig. 6a) and 8 weeks $(p=0.0004$, Fig. 6b). COMP levels in the xELP[IL-1Ra+sTNFRII] group were also significantly different compared to the Non-fx group at 4 weeks ( $p=0.0009$ ). Serum COMP levels (Fig. 6c) were significantly lower in the xELP[IL-1Ra] group compared with the $x E L P[I L-1 R a+s T N F R I I]$ group at 4 weeks $(p=0.031)$ and similar to levels in the non-Fx group. At 8 weeks, serum COMP levels in the Non-fx group were significantly lower compared to the XELP[PBS] group $(p=0.035)$. Serum MMP-3 levels decreased compared to Non-fx controls when IL-1Ra was delivered either alone (xELP[IL-1Ra], $p=0.041$ ) or in combination with sTNFRII (xELP[IL-1Ra+sTNFRII], $p=0.034$ ) at 4 weeks (Fig. 6d). No differences were seen at 8 weeks. Serum IL-6 (Table 1) showed a significant difference at 4 weeks between the Non-fx group and the xELP[PBS] group $(p=0.015)$ and between the Non-fx group and the $\mathrm{xELP}[\mathrm{IL}-1 \mathrm{Ra}+\mathrm{sTNFRII}]$ group $(p=0.0025)$, but no differences at 8 weeks. Serum levels of HA and MDC (Table 1) did not show any differences between groups at 4 or 8 weeks. Serum levels of TARC (Table 1) showed a significant difference between the xELP[PBS] group and the $x E L P[s T N F R I I]$ group at 4 weeks $(p=0.023)$, but did not show differences at 8 weeks. Free active TGF- $\beta_{1}$ in serum (Table 1) showed few differences among groups with the exception of higher concentrations in the XELP[IL$1 \mathrm{Ra}+\mathrm{sTNFRII}]$ group compared to the $\mathrm{xELP}[\mathrm{PBS}]$ group at 8 weeks $(p=0.0086)$.

\section{Correlations between biomarkers, histology, and bone morphology}

Despite the limited amount of differences between groups at both 4 and 8 weeks, there were interesting correlations between the biomarkers and Mankin scores, synovitis 
scores, and bone properties. For example, the synovial fluid COMP levels in the fractured limb positively correlated with the synovitis score of the fractured limb at both 4 and 8 weeks $\left(r_{s}=0.69, p=0.00001 ; r_{s}=0.41\right.$, $p=0.0094$ ), and the IL-6 serum levels negatively correlated with the synovitis score of the fractured limb at 4 weeks $\left(r_{s}=-0.50, p=0.0016\right)$. Biomarkers also correlated with other biomarkers; for example, the fractured limb synovial fluid COMP levels positively correlated with the serum COMP levels at 4 weeks $\left(r_{s}=0.41, p=0.0055\right)$. IL-6 serum positively correlated with serum MMP-3 levels at 4 weeks $\left(r_{s}=0.39, p=0.0093\right)$. Synovial fluid COMP levels from the fractured limb did not correlate with serum MMP-3 levels at 4 weeks; however, synovial fluid COMP negatively correlated with the serum MMP-3 levels $\left(r_{s}=-0.34, p=0.020\right)$ at 8 weeks. Serum MMP-3 also positively correlated with the serum $\operatorname{COMP}\left(r_{s}=0.30\right.$, $p=0.048)$ and negatively correlated with serum MDC at 8 weeks $\left(r_{s}=-0.34, p=0.020\right)$.

\section{Discussion}

This study demonstrated that sustained release of IL-1Ra in the joint space reduced the severity of arthritic changes in both cartilage and synovium following intra-articular fracture. In contrast, the sustained delivery of sTNFRII alone in the joint space, or in combination with IL-1Ra, resulted in detrimental bone, cartilage, and synovial changes. Importantly, we found that cross-linked ELPs provided for the entrapment of the protein drugs studied here, and for the sustained release observed in vitro and in vivo following intra-articular delivery. These findings demonstrate the potential of a beneficial therapeutic approach as an adjunct to surgical treatment for the prevention of PTA: the sustained intra-articular release of IL-1Ra significantly reduced the development of PTA following articular fracture when used in combination with cross-linked ELP as a thermally-sensitive drug depot.

Sustained administration of IL-1Ra reduced the level of cartilage degeneration in the joint and did not detrimentally affect bone healing. Other studies have shown similar results with the use of IL-1Ra; for instance, Lange and coworkers found that inactivating IL-1RI in mice did not affect long bone healing (Lange et al., 2010). We did not observe detrimental effects on bone healing or bone morphological changes in the xELP[IL-1Ra] treatment group. The mice that received IL-1Ra exhibited a significantly smaller decrease in both bone volume and bone density compared to the sTNFRII and IL-1Ra+sTNFRII groups. These data support the conclusion that bone healing was not adversely affected by the presence of IL-1Ra, while the addition of TNFRII via an intra-articular route did alter bone healing.

In our study, the Mankin scores of the IL-1Ra group were decreased compared to the sTNFRII and IL$1 \mathrm{Ra}+\mathrm{sTNFRII}$ groups at both 4 and 8 weeks, providing evidence that IL-1Ra has some protective effect on articular cartilage after articular fracture compared to no treatment. Examination of the histologic sections also provided evidence of this protective effect; cartilage from the IL-1Ra group had the most intact structure and robust staining compared to the other groups. The results suggest that the PBS group also showed reduced articular cartilage degeneration compared to the no treatment group, which may be due to a washing-out effect. The Mankin score of the PBS group showed a trend towards being significant at 8 weeks, unlike the IL-1Ra group. In a previous study, we showed that the administration of local saline reduced degenerative bone changes; however, it did not reduce cartilage degeneration or synovial inflammation (Furman et al., 2014b). We also examined the synovium in our joints in order to grade the severity of synovitis as a result of articular fracture. Based on Mankin and synovitis scores, it is evident that degenerative changes occur globally throughout the joint in this mouse fracture model. At 8 weeks after fracture, the synovitis scores showed that the IL-1Ra and PBS groups were the only groups without a significant difference between the fractured limb and control on the medial side of the joint. However, the IL-1Ra group was the only group without a significant difference on the lateral side where the fracture occurred. The difference between limbs on the lateral side was significantly different for all the other groups. This finding shows that IL-1Ra not only reduced the level of cartilage degeneration, but also reduced the amount of synovitis in the joint. These findings are consistent with results of Caron and co-workers who showed that twice weekly injections of recombinant human IL-1Ra (rHuIL-1Ra) for four weeks demonstrated a chondroprotective effect against the development of OA after anterior cruciate ligament (ACL) transection in a canine model compared to saline control (Caron et al., 1996), although the presence of an articular fracture in our model represents additional factors related to bone fracture and trauma that may lead to more rapid or severe degeneration. In a previous study, we showed that a single local injection of IL-1Ra given after articular fracture was able to reduce articular cartilage degeneration; however, systemic administration of IL-1Ra resulted in significant differences in Mankin scores between control and fractured limbs (Furman et al., 2014b). These results underscore the utility of this model system for assessing PTA severity and for identifying new therapies for this disease process in humans.

In contrast to the effectiveness of IL-1Ra on the fractured joints in our model, sTNFRII did not provide protection against PTA. Bone healing was inhibited in the presence of sTNFRII, which may have contributed to the lack of protection against PTA changes. In our study, we did not observe the same effectiveness of sTNFRII as seen in previous studies focused on RA (Bathon et al., 2006; Bliddal et al., 2006; Boesen et al., 2008; Fiocco et al., 2010; Johnsen et al., 2006; Kavanaugh et al., 2008; Krieckaert et al., 2012; Moreland et al., 1999; Roux et al., 2011; Zwerina et al., 2004). Similarly, Gerstenfeld and coworkers reported that a long bone fracture of the tibia in TNF receptor knockout mice resulted in non-union of the fracture (Gerstenfeld et al., 2003). In our study, we also observed the detrimental effect of sTNFRII on bone morphology. Compared to the fracture only group, the sTNFRII and the IL-1Ra+sTNFRII groups showed a significant decrease in bone volume, while the sTNFRII group also showed a significant decrease in bone density. A similar result was 
seen for articular cartilage degeneration; the sTNFRII and IL-1Ra+sTNFRII groups had a significantly higher Mankin score in the fractured limb compared to the contralateral control limb at 8 weeks. Elsaid and co-workers showed that blocking TNF- $\alpha$ in an ACL-transection model reduced the loss of GAG from articular cartilage (Elsaid et al., 2009); however, in our case, the articular fracture plus the inhibition of TNF- $\alpha$ led to the irreversible damage of the articular cartilage, as reflected in the histological scores of the two sTNFRII groups. The neutral or positive impact of TNF- $\alpha$ inhibition on soft tissue injury healing contrasted with the negative impact on bone fracture healing suggests that TNF- $\alpha$ is necessary for the fracture healing cascade (Fazzalari, 2011). This might indicate why the two groups that received sTNFRII had such poor results compared to the other groups. We also noticed an increase in synovitis in the two groups that received sTNFRII; in fact, synovial proliferation in these groups was so great that it was extremely difficult to identify where the synovium attached to the joints. Both the sTNFRII and IL-1Ra+sTNFRII groups showed a significant difference between the fractured limb and the contralateral control limb on the medial and lateral side at 8 weeks. The loss of TNF- $\alpha$ not only affected bone healing, but also increased the level of inflammation present in the joint after trauma. The timing of administration of sTNFRII after injury may alter the effect of blocking TNF- $\alpha$; however, from our study, inhibiting TNF- $\alpha$ immediately after injury proved deleterious. Systemic delivery of both IL-1Ra and sTNFRII in combination was also harmful; however, despite the increased risk of infection and contraindications (McEvoy, 2006) associated with administering both IL-1 and TNF inhibitors simultaneously, none of our mice showed signs of infection after an intra-articular injection of xELP[IL$1 \mathrm{Ra}+\mathrm{sTNFRII}]$.

An important finding of this study was the successful use of cross-linked ELP as a sustained-release drug depot for intra-articular anti-cytokine therapy. In previous studies, a fusion protein of ELP with IL-1Ra was shown to preserve the characteristics of both ELP and IL-1Ra and serve as a sustained-release delivery method for intra-articular therapy (Shamji et al., 2007). Adams and co-workers demonstrated efficacy for this ELP-IL1Ra fusion protein against IL-1-induced arthritis in a rat model as compared to a single injection of low dose IL-1Ra (Allen et al., 2010). Encapsulation of drug provides some significant advantages over drug fusions, namely, the ability to increase drug-loading ratios and to work with unmodified, native, and FDA-approved drugs. Adams and co-workers also demonstrated proof-of-concept for cross-linked ELPs to encapsulate antibiotics, retain the ELP thermal transitioning properties, and slowly release drug over a number of days (Adams et al., 2009). Previous studies have demonstrated that the intra-articular half-life of 15-30 kDa proteins is as little as 2-4 h (Betre et al., 2006a), while clinical studies have shown clearance of the $17.3 \mathrm{kDa}$ IL-1Ra by $7.4 \mathrm{~h}$ following intra-articular delivery in the human body (Chevalier et al., 2009). These short half-lives for soluble protein drugs argues for the delivery in depot forms that can sequester the drug from the soluble compartment, thus providing for sustained release following dis-equilibria from the drug-loaded depot. Because of the rapid inflammatory response immediately after joint trauma, we wished to provide immediate and sustained exposure of intra-articular tissues to IL-1Ra to help reduce the acute inflammatory response post-fracture. This study confirmed that IL-1Ra is detectable in serum up to at least $5 \mathrm{~d}$ after injection, indicating that $\mathrm{xELP}$ depots can provide a sustained IL-1Ra release that is not obtainable with a single intra-articular injection of nonconjugated IL-1Ra. Similarly, sTNFRII was also detectable in the serum of mice $5 \mathrm{~d}$ after intra-articular injection. The large difference in size between IL-1Ra $(17.3 \mathrm{kDa})$ and sTNFRII $(150 \mathrm{kDa})$ indicates that XELP can encapsulate a range of different sized molecules, underscoring its potential to be used for the delivery of a variety of drugs of many sizes. There are a wide range of ELPs that have been designed for various applications, such as drug delivery and tissue engineering (Betre et al., 2006a; Chilkoti et al., 2002a; Chilkoti et al., 2002b; MacEwan and Chilkoti, 2009; Megeed et al., 2002; Nettles et al., 2010); currently, ELP is being used in type-2 diabetes human clinical trials to deliver glucagon-like peptide-1, a diabetes drug (Amiram et al., 2013), and has the potential to influence the treatment of other diseases in the future.

Biomarkers have been used to non-invasively identify and monitor the progression of diseases such as PTA (Hazell et al., 1995; Lindhorst et al., 2000; Saxne and Heinegard, 1992). Levels of certain serum and synovial fluid biomarkers, such as COMP, may be indicative of cellular processes and the level of damage caused by joint disease. Levels of COMP, HA, and IL-6 were previously examined in an acute mouse fracture model with HA significantly upregulated acutely after fracture (Lewis et al., 2013). Macrophage chemokines such as MDC and TARC were selected for examination since our previous work demonstrated significant upregulation in gene expression in mouse strains after a tibial plateau fracture (Lewis et al., 2013) and in cytokine levels in humans after ankle fracture (Furman et al., 2014a). Human clinical studies have also shown that TGF- $\beta_{1}$ correlates with the degree of fracture healing in long bone fractures (Sarahrudi et al., 2011; Zimmermann et al., 2005; Zimmermann et al., 2007), so we examined the levels of free active and total TGF- $\beta_{1}$ in serum. Matrix metalloproteinase 3 (MMP-3) has been associated with tissue breakdown and remodeling in arthritis; previous studies have shown some correlation with OA (Kubota et al., 1997; Mahmoud et al., 2005; Ribbens et al., 2002), so we examined the levels of serum MMP-3 in our study. Although our biomarker analyses revealed relatively few differences between the treatment groups, we saw correlations of biomarkers with both joint tissue and bone properties, highlighting the complex interaction of bone, joint tissue, and biomarkers following trauma. Because the majority of these differences were seen at 4 weeks, the biomarkers that we measured - COMP, TGF- $\beta_{1}$, IL-6, HA, MMP-3, MDC and TARC - may be better predictive of changes that occur during the acute phase of injury rather than the 4 to 8 week period after injury that we examined.

The promising results with XELP[IL-1Ra] could provide a novel adjunct therapy combined with surgical 
stabilization of the joint to reduce or prevent PTA. The use of IL-1Ra has been FDA approved for RA and shown to have short-term efficacy for pain and function after soft tissue injury in the knee (Kraus et al., 2012). ELP is currently being used in diabetes clinical trials (Amiram et al., 2013), which would allow for the ease of transitioning $\mathrm{xELP}$ [IL-1Ra] from the laboratory to human trials. Nonetheless, future studies are needed to examine the long-term safety and efficacy of this approach as a therapy for PTA in humans.

\section{Conclusions}

Currently, surgical restoration is the primary treatment for articular fractures; however, PTA frequently develops following joint trauma despite appropriate surgical reduction and fixation. Our study identifies the potential for prolonged anti-cytokine therapy to serve as an adjunct therapy to current surgical stabilization. IL-1Ra decreased the osteoarthritic damage caused by PTA, indicating that IL-1 plays a role in the destruction caused by PTA after articular fractures. The use of XELP for sustained intraarticular delivery of a therapeutic in the form of XELP[IL$1 \mathrm{Ra}$ ] holds great promise as a new treatment for PTA.

\section{Acknowledgments}

The authors would like to thank Steve Johnson for his technical support, and Dr. Dana Nettles, Dovina Qu, Dr. Holly Leddy, Chia-Lung Wu, Dr. Nicole Zelenski, Nicole Rothfusz, Dr. Christopher O'Connor, and Elisabeth Flannery for their assistance during the study. The work in this study was supported by grants from the Department of Defense (W81XWH-10-1-0890), NIH grants AR050245, AG015768, AR048182, AR048852, AG046927, AR047442, the Arthritis Foundation, and Synthes. We wish to confirm that there are no known conflicts of interest associated with this publication and there has been no significant financial support for this work that could have influenced its outcome.

\section{References}

Abramson SB, Yazici Y (2006) Biologics in development for rheumatoid arthritis: relevance to osteoarthritis. Adv Drug Deliv Rev 58: 212-225.

Adams SB Jr, Shamji MF, Nettles DL, Hwang P, Setton LA (2009) Sustained release of antibiotics from injectable and thermally responsive polypeptide depots. J Biomed Mater Res B Appl Biomater 90: 67-74.

Allen KD, Adams SB, Setton LA (2010) Evaluating intra-articular drug delivery for the treatment of osteoarthritis in a rat model. Tissue Eng Part B Rev 16: 81-92.

Allen KD, Adams SB Jr, Mata BA, Shamji MF, Gouze E, Jing L, Nettles DL, Latt LD, Setton LA (2011) Gait and behavior in an IL1 beta-mediated model of rat knee arthritis and effects of an IL1 antagonist. J Orthop Res 29: 694-703.
Amiram M, Luginbuhl KM, Li X, Feinglos MN, Chilkoti A (2013) A depot-forming glucagon-like peptide-1 fusion protein reduces blood glucose for five days with a single injection. J Control Release 172: 144-151.

Bathon JM, Fleischmann RM, Van der Heijde D, Tesser JR, Peloso PM, Chon Y, White B (2006) Safety and efficacy of etanercept treatment in elderly subjects with rheumatoid arthritis. J Rheumatol 33: 234-243.

Betre H, Liu W, Zalutsky MR, Chilkoti A, Kraus VB, Setton LA (2006a) A thermally responsive biopolymer for intra-articular drug delivery. J Control Release 115: 175182.

Bigoni M, Sacerdote P, Turati M, Franchi S, Gandolla M, Gaddi D, Moretti S, Munegato D, Augusti CA, Bresciani E, Omeljaniuk RJ, Locatelli V, Torsello A (2013) Acute and late changes in intraarticular cytokine levels following anterior cruciate ligament injury. J Orthop Res 31: 315-321.

Bliddal H, Terslev L, Qvistgaard E, Konig M, Holm CC, Rogind H, Boesen M, Danneskiold-Samsoe B, Torp-Pedersen S (2006) A randomized, controlled study of a single intra-articular injection of etanercept or glucocorticosteroids in patients with rheumatoid arthritis. Scand J Rheumatol 35: 341-345.

Boesen M, Boesen L, Jensen KE, Cimmino MA, TorpPedersen S, Terslev L, Koenig M, Danneskiold-Samsoe B, Rogind H, Bliddal H (2008) Clinical outcome and imaging changes after intraarticular (IA) application of etanercept or methylprednisolone in rheumatoid arthritis: magnetic resonance imaging and ultrasound-Doppler show no effect of IA injections in the wrist after 4 weeks. J Rheumatol 35: 584-591.

Bresnihan B, Alvaro-Gracia JM, Cobby M, Doherty M, Domljan Z, Emery P, Nuki G, Pavelka K, Rau R, Rozman B, Watt I, Williams B, Aitchison R, McCabe D, Musikic P (1998) Treatment of rheumatoid arthritis with recombinant human interleukin-1 receptor antagonist. Arthritis Rheum 41: 2196-2204.

Brown TD, Johnston RC, Saltzman CL, Marsh JL, Buckwalter JA (2006) Posttraumatic osteoarthritis: a first estimate of incidence, prevalence, and burden of disease. J Orthop Trauma 20: 739-744.

Buckwalter JA, Brown TD (2004) Joint injury, repair, and remodeling: roles in post-traumatic osteoarthritis. Clin Orthop Relat Res 423: 7-16.

Cameron M, Buchgraber A, Passler H, Vogt M, Thonar E, Fu F, Evans CH (1997) The natural history of the anterior cruciate ligament-deficient knee. Changes in synovial fluid cytokine and keratan sulfate concentrations. Am J Sports Med 25: 751-754.

Caron JP, Fernandes JC, Martel-Pelletier J, Tardif G, Mineau F, Geng C, Pelletier JP (1996) Chondroprotective effect of intraarticular injections of interleukin-1 receptor antagonist in experimental osteoarthritis. Suppression of collagenase-1 expression. Arthritis Rheum 39: 1535-1544.

Chevalier X, Giraudeau B, Conrozier T, Marliere J, Kiefer P, Goupille P (2005) Safety study of intraarticular injection of interleukin 1 receptor antagonist in patients with painful knee osteoarthritis: a multicenter study. J Rheumatol 32: 1317-1323. 
Chevalier X, Goupille P, Beaulieu AD, Burch FX, Bensen WG, Conrozier T, Loeuille D, Kivitz AJ, Silver D, Appleton BE (2009) Intraarticular injection of anakinra in osteoarthritis of the knee: a multicenter, randomized, double-blind, placebo-controlled study. Arthritis Rheum 61: 344-352.

Chilkoti A, Dreher MR, Meyer DE (2002a) Design of thermally responsive, recombinant polypeptide carriers for targeted drug delivery. Adv Drug Deliv Rev 54: 1093-1111.

Chilkoti A, Dreher MR, Meyer DE, Raucher D (2002b) Targeted drug delivery by thermally responsive polymers. Adv Drug Deliv Rev 54: 613-630.

Cole P, Levy B, Schatzker J, Watson JT (2009) Tibial plateau fractures. In: Browner BD, Levine AM, Jupiter JB, Trafton PG (eds) Skeletal Trauma: Basic Science, Management, and Reconstruction, Saunders/Elsevier, Philadelphia, pp 2201-2288.

Elsaid KA, Machan JT, Waller K, Fleming BC, Jay GD (2009) The impact of anterior cruciate ligament injury on lubricin metabolism and the effect of inhibiting tumor necrosis factor alpha on chondroprotection in an animal model. Arthritis Rheum 60: 2997-3006.

Evans CH, Kraus VB, Setton LA (2014) Progress in intra-articular therapy. Nat Rev Rheumatol 10: 11-22.

Fazzalari NL (2011) Bone fracture and bone fracture repair. Osteoporos Int 22: 2003-2006.

Fernandes JC, Martel-Pelletier J, Pelletier JP (2002) The role of cytokines in osteoarthritis pathophysiology. Biorheology 39: 237-246.

Fiocco U, Sfriso P, Oliviero F, Roux-Lombard P, Scagliori E, Cozzi L, Lunardi F, Calabrese F, Vezzu M, Dainese S, Molena B, Scanu A, Nardacchione R, Rubaltelli L, Dayer JM, Punzi L (2010) Synovial effusion and synovial fluid biomarkers in psoriatic arthritis to assess intraarticular tumor necrosis factor-alpha blockade in the knee joint. Arthritis Res Ther 12: R148.

Fleischmann R (2006) Anakinra in the treatment of rheumatic disease. Expert Rev Clin Immunol 2: 331-340.

Fleischmann RM, Baumgartner SW, Tindall EA, Weaver AL, Moreland LW, Schiff MH, Martin RW, Spencer-Green GT (2003a) Response to etanercept (Enbrel) in elderly patients with rheumatoid arthritis: a retrospective analysis of clinical trial results. J Rheumatol 30: 691-696.

Fleischmann RM, Schechtman J, Bennett R, Handel ML, Burmester GR, Tesser J, Modafferi D, Poulakos J, Sun G (2003b) Anakinra, a recombinant human interleukin-1 receptor antagonist (r-metHuIL-1ra), in patients with rheumatoid arthritis: A large, international, multicenter, placebo-controlled trial. Arthritis Rheum 48: 927-934.

Fleischmann R, Baumgartner SW, Weisman MH, Liu T, White B, Peloso P (2006a) Long term safety of etanercept in elderly subjects with rheumatic diseases. Ann Rheum Dis 65: $379-384$.

Fleischmann RM, Tesser J, Schiff MH, Schechtman J, Burmester GR, Bennett R, Modafferi D, Zhou L, Bell D, Appleton B (2006b) Safety of extended treatment with anakinra in patients with rheumatoid arthritis. Ann Rheum Dis 65: 1006-1012.
Fukui N, Purple CR, Sandell LJ (2001) Cell biology of osteoarthritis: the chondrocyte's response to injury. Curr Rheumatol Rep 3: 496-505.

Furman BD, Olson SA, Guilak F (2006) The development of posttraumatic arthritis after articular fracture. J Orthop Trauma 20: 719-725.

Furman BD, Strand J, Hembree WC, Ward BD, Guilak F, Olson SA (2007) Joint degeneration following closed intraarticular fracture in the mouse knee: a model of posttraumatic arthritis. J Orthop Res 25: 578-592.

Furman BD, Kimmerling KA, Huebner JL, Kraus VB, Guilak F, Olson SA (2014a) Articular fracture in the ankle results in increased acute local inflammation. Transactions of the Annual Meeting of the Orthopaedic Research Society, New Orleans, LA, p 1069.

Furman BD, Mangiapani DS, Zeitler E, Bailey KN, Horne PH, Huebner JL, Kraus VB, Guilak F, Olson SA (2014b) Targeting pro-inflammatory cytokines following joint injury: acute intra-articular inhibition of interleukin-1 following knee injury prevents post-traumatic arthritis. Arthritis Res Ther 16: R134.

Gerstenfeld LC, Cho TJ, Kon T, Aizawa T, Tsay A, Fitch J, Barnes GL, Graves DT, Einhorn TA (2003) Impaired fracture healing in the absence of TNF-alpha signaling: the role of TNF-alpha in endochondral cartilage resorption. J Bone Miner Res 18: 1584-1592.

Gorth DJ, Mauck RL, Chiaro JA, Mohanraj B, Hebela NM, Dodge GR, Elliott DM, Smith LJ (2012) IL-1ra delivered from poly(lactic-co-glycolic acid) microspheres attenuates IL-1beta-mediated degradation of nucleus pulposus in vitro. Arthritis Res Ther 14: R179.

Guler-Yuksel M, Allaart CF, Watt I, GoekoopRuiterman YP, de Vries-Bouwstra JK, van Schaardenburg D, van Krugten MV, Dijkmans BA, Huizinga TW, Lems WF, Kloppenburg M (2010) Treatment with TNF-alpha inhibitor infliximab might reduce hand osteoarthritis in patients with rheumatoid arthritis. Osteoarthritis Cartilage 18: 1256-1262.

Hazell PK, Dent C, Fairclough JA, Bayliss MT, Hardingham TE (1995) Changes in glycosaminoglycan epitope levels in knee joint fluid following injury. Arthritis Rheum 38: 953-959.

Higuchi H, Shirakura K, Kimura M, Terauchi M, Shinozaki T, Watanabe H, Takagishi K (2006) Changes in biochemical parameters after anterior cruciate ligament injury. Int Orthop 30: 43-47.

Irie K, Uchiyama E, Iwaso H (2003) Intraarticular inflammatory cytokines in acute anterior cruciate ligament injured knee. Knee 10: 93-96.

Johnsen AK, Schiff MH, Mease PJ, Moreland LW, Maier AL, Coblyn JS, Helfgott SM, Leff JA, Weinblatt ME (2006) Comparison of 2 doses of etanercept (50 vs. 100 $\mathrm{mg}$ ) in active rheumatoid arthritis: a randomized double blind study. J Rheumatol 33: 659-664.

Kavanaugh A, Klareskog L, van der Heijde D, Li J, Freundlich B, Hooper M (2008) Improvements in clinical response between 12 and 24 weeks in patients with rheumatoid arthritis on etanercept therapy with or without methotrexate. Ann Rheum Dis 67: 1444-1447. 
Kraus VB, Birmingham J, Stabler TV, Feng S, Taylor DC, Moorman CT 3rd, Garrett WE, Toth AP (2012) Effects of intraarticular IL1-Ra for acute anterior cruciate ligament knee injury: a randomized controlled pilot trial (NCT00332254). Osteoarthritis Cartilage 20: 271-278.

Krieckaert CL, Jamnitski A, Nurmohamed MT, Kostense PJ, Boers M, Wolbink G (2012) Comparison of long-term clinical outcome with etanercept treatment and adalimumab treatment of rheumatoid arthritis with respect to immunogenicity. Arthritis Rheum 64: 3850-3855.

Kubota E, Imamura H, Kubota T, Shibata T, Murakami K (1997) Interleukin 1 beta and stromelysin (MMP3) activity of synovial fluid as possible markers of osteoarthritis in the temporomandibular joint. J Oral Maxillofac Surg 55: 20-27.

Lange J, Sapozhnikova A, Lu C, Hu D, Li X, Micalu $\mathrm{T}$, Marcucio RS (2010) Action of IL-1 $\beta$ during fracture healing. J Orthop Res 28: 778-784.

Larsen C, Ostergaard J, Larsen SW, Jensen H, Jacobsen S, Lindegaard C, Andersen PH (2008) Intra-articular depot formulation principles: role in the management of postoperative pain and arthritic disorders. J Pharm Sci 97: 4622-4654.

Lawrence RC, Felson DT, Helmick CG, Arnold LM, Choi H, Deyo RA, Gabriel S, Hirsch R, Hochberg MC, Hunder GG, Jordan JM, Katz JN, Kremers HM, Wolfe F, National Arthritis Data Workgroup (2008) Estimates of the prevalence of arthritis and other rheumatic conditions in the United States. Part II. Arthritis Rheum 58: 26-35.

Lewis JS Jr, Furman BD, Zeitler E, Huebner JL, Kraus VB, Guilak F, Olson SA (2013) Genetic and cellular evidence of decreased inflammation associated with reduced post-traumatic arthritis in $\mathrm{MRL} / \mathrm{MpJ}$ mice. Arthritis Rheum 65: 660-670.

Lim DW, Nettles DL, Setton LA, Chilkoti A (2007) Rapid cross-linking of elastin-like polypeptides with (hydroxymethyl)phosphines in aqueous solution. Biomacromolecules 8: 1463-1470.

Lim DW, Nettles DL, Setton LA, Chilkoti A (2008) In situ cross-linking of elastin-like polypeptide block copolymers for tissue repair. Biomacromolecules 9: 222230.

Lindhorst E, Vail TP, Guilak F, Wang H, Setton LA, Vilim V, Kraus VB (2000) Longitudinal characterization of synovial fluid biomarkers in the canine meniscectomy model of osteoarthritis. J Orthop Res 18: 269-280.

MacEwan SR, Chilkoti A (2009) Elastin-like polypeptides: biomedical applications of tunable biopolymers. Peptide Sci 94: 60-77.

Magnano MD, Chakravarty EF, Broudy C, Chung L, Kelman A, Hillygus J, Genovese MC (2007) A pilot study of tumor necrosis factor inhibition in erosive/inflammatory osteoarthritis of the hands. J Rheumatol 34: 1323-1327.

Mahmoud RK, El-Ansary AK, El-Eishi HH, Kamal HM, El-Saeed NH (2005) Matrix metalloproteinases MMP-3 and MMP-1 levels in sera and synovial fluids in patients with rheumatoid arthritis and osteoarthritis. Ital J Biochem 54: 248-257.

Mangiapani DS, Zeitler E, Furman BD, Huebner JL, Kraus VB, Guilak F, Olson SA (2012) Inhibition of interleukin-1 prevents post-traumatic arthritis following articular fracture in the mouse knee. Transactions of the Annual Meeing of the Orthopaedic Research Society, San Francisco, CA, p 711.

Marks PH, Donaldson ML (2005) Inflammatory cytokine profiles associated with chondral damage in the anterior cruciate ligament-deficient knee. Arthroscopy 21: 1342-1347.

McEvoy G (2006) AHFS Drug Information 2006. American Society of Health-System Pharmacists, Bethesda, MD.

McNulty AL, Rothfusz NE, Leddy HA, Guilak F (2013) Synovial fluid concentrations and relative potency of interleukin-1 alpha and beta in cartilage and meniscus degradation. J Orthop Res 31: 1039-1045.

Megeed Z, Cappello J, Ghandehari H (2002) Genetically engineered silk-elastinlike protein polymers for controlled drug delivery. Adv Drug Deliv Rev 54: 1075-1091.

Meyer DE, Chilkoti A (2002) Genetically encoded synthesis of protein-based polymers with precisely specified molecular weight and sequence by recursive directional ligation: examples from the elastin-like polypeptide system. Biomacromolecules 3: 357-367.

Moreland LW, Schiff MH, Baumgartner SW, Tindall EA, Fleischmann RM, Bulpitt KJ, Weaver AL, Keystone EC, Furst DE, Mease PJ, Ruderman EM, Horwitz DA, Arkfeld DG, Garrison L, Burge DJ, Blosch CM, Lange ML, McDonnell ND, Weinblatt ME (1999) Etanercept therapy in rheumatoid arthritis. A randomized, controlled trial. Ann Intern Med 130: 478-486.

Mountziaris PM, Mikos AG (2008) Modulation of the inflammatory response for enhanced bone tissue regeneration. Tissue Eng Part B Rev 14: 179-186.

Nettles DL, Chilkoti A, Setton LA (2010) Applications of elastin-like polypeptides in tissue engineering. Adv Drug Deliv Rev 62: 1479-1485.

Nuki G, Bresnihan B, Bear MB, McCabe D, European Group Of Clinical Investigators (2002) Long-term safety and maintenance of clinical improvement following treatment with anakinra (recombinant human interleukin-1 receptor antagonist) in patients with rheumatoid arthritis: extension phase of a randomized, double-blind, placebocontrolled trial. Arthritis Rheum 46: 2838-2846.

Patzkowski JC, Rivera JC, Ficke JR, Wenke JC (2012) The changing face of disability in the US Army: the Operation Enduring Freedom and Operation Iraqi Freedom effect. J Am Acad Orthop Surg 20 Suppl 1: S23-30.

Ribbens C, Martin y Porras M, Franchimont N, Kaiser MJ, Jaspar JM, Damas P, Houssiau FA, Malaise MG (2002) Increased matrix metalloproteinase-3 serum levels in rheumatic diseases: relationship with synovitis and steroid treatment. Ann Rheum Dis 61: 161-166.

Rivera JC, Wenke JC, Buckwalter JA, Ficke JR, Johnson AE (2012) Posttraumatic osteoarthritis caused by battlefield injuries: the primary source of disability in warriors. J Am Acad Orthop Surg 20 Suppl 1: S64-69.

Roux CH, Breuil V, Valerio L, Amoretti N, Brocq O, Albert C, Grisot C, Allam Y, Chevalier P, Pradier C, EullerZiegler L (2011) Etanercept compared to intraarticular corticosteroid injection in rheumatoid arthritis: doubleblind, randomized pilot study. J Rheumatol 38: 1009-1011. 
Sarahrudi K, Thomas A, Mousavi M, Kaiser G, Kottstorfer J, Kecht M, Hajdu S, Aharinejad S (2011) Elevated transforming growth factor-beta 1 (TGF-beta1) levels in human fracture healing. Injury 42: 833-837.

Saxne T, Heinegard D (1992) Cartilage oligomeric matrix protein: a novel marker of cartilage turnover detectable in synovial fluid and blood. Br J Rheumatol 31: 583-591.

Seifer DR, Furman BD, Guilak F, Olson SA, Brooks SC 3rd, Kraus VB (2008) Novel synovial fluid recovery method allows for quantification of a marker of arthritis in mice. Osteoarthritis Cartilage 16: 1532-1538.

Shamji MF, Betre H, Kraus VB, Chen J, Chilkoti A, Pichika R, Masuda K, Setton LA (2007) Development and characterization of a fusion protein between thermally responsive elastin-like polypeptide and interleukin-1 receptor antagonist: sustained release of a local antiinflammatory therapeutic. Arthritis Rheum 56: 3650-3661.

Sward P, Frobell R, Englund M, Roos H, Struglics A (2012) Cartilage and bone markers and inflammatory cytokines are increased in synovial fluid in the acute phase of knee injury (hemarthrosis) - a cross-sectional analysis. Osteoarthritis Cartilage 20: 1302-1308.

Tejeda-Montes E, Smith KH, Poch M, Lopez-Bosque MJ, Martin L, Alonso M, Engel E, Mata A (2012) Engineering membrane scaffolds with both physical and biomolecular signaling. Acta Biomater 8: 998-1009.

Trabbic-Carlson K, Setton LA, Chilkoti A (2003) Swelling and mechanical behaviors of chemically cross-linked hydrogels of elastin-like polypeptides. Biomacromolecules 4: 572-580.

Urry DW (1992) Free energy transduction in polypeptides and proteins based on inverse temperature transitions. Prog Biophys Mol Biol 57: 23-57.

Urry DW (1997) Physical chemistry of biological free energy transduction as demonstrated by elastic proteinbased polymers. J Phys Chem B 101: 11007-11028.

Urry DW, Pattanaik A, Xu J, Woods TC, McPherson DT, Parker TM (1998) Elastic protein-based polymers in soft tissue augmentation and generation. J Biomater Sci Polym Ed 9: 1015-1048.

Zimmermann G, Henle P, Kusswetter M, Moghaddam A, Wentzensen A, Richter W, Weiss S (2005) TGF-beta1 as a marker of delayed fracture healing. Bone 36: 779-785.

Zimmermann G, Moghaddam A, Reumann M, Wangler B, Breier L, Wentzensen A, Henle P, Weiss S (2007) TGF- $\beta 1$ als pathophysiologischer Faktor bei der Frakturheilung. [TGF-beta1 as a pathophysiological factor in fracture healing.] Unfallchirurg 110: 130-136.

Zwerina J, Hayer S, Tohidast-Akrad M, Bergmeister H, Redlich K, Feige U, Dunstan C, Kollias G, Steiner G, Smolen J, Schett G (2004) Single and combined inhibition of tumor necrosis factor, interleukin-1, and RANKL pathways in tumor necrosis factor-induced arthritis: effects on synovial inflammation, bone erosion, and cartilage destruction. Arthritis Rheum 50: 277-290.

\section{Discussion with Reviewers}

Reviewer I: Are there any signs of a humoral immune response to the large dose of ELP-matrix delivered in the joint? Is this a potential concern?

Authors: There was no evidence of a humoral immune response to the dose of ELP delivered to the joint in any of the mice sacrificed in our study. ELP was used as a drug depot because of its non-immunogenic properties; previous studies by Urry and coauthors have shown that repeated injections of ELPs into Balb/c, DBA, and CB6F1 mice failed to produce specific hybridomas, and therefore, no immune response to the material (Urry et al., 1998). On the cellular level, studies by Picciolo et al. (1993) showed that ELPs were not recognized as a foreign substance when introduced to cells, leading to no immune response. Based on these and other studies, ELPs are not a potential concern for a humoral immune response when used as an intra-articular drug depot.

Reviewer I: It is not clear whether the ELP matrix serves a protein delivery role unique to its composition and degradative properties, or simply functions to impede diffusion of the loaded protein drug and thus provide prolonged delivery.

Authors: ELPs in general can support both of these roles; in our study, the ELP matrix served to impede diffusion of the loaded IL-1Ra or sTNFRII to provide prolonged delivery to the joint. A previous study conducted by our group examined the effect of a single intra-articular injection versus a systemic administration of IL-1Ra and sTNFRII separately. It was shown that systemic administration of the drugs via osmotic pump (IL-1Ra) or subcutaneous injections (sTNFRII) did not provide a benefit, nor did local delivery of sTNFRII (Furman et al., 2014b). A single local intra-articular injection of IL-1Ra reduced cartilage degeneration, synovial inflammation, and did not affect bone morphology following articular fracture. The idea behind using the ELP was to take the dosage that was delivered in the single local injection $-0.9 \mathrm{mg}$ IL-1Ra - cut it in half, and keep it in the joint space longer. One of the issues with using IL-1Ra for the treatment of OA is that it has an incredibly short half-life (4.7 h) (Chevalier et al., 2009), so the fact that we could detect IL-1Ra in the joint space at $5 \mathrm{~d}$ demonstrates that the ELP is acting to prolong the delivery of the drug to the injury site.

Reviewer I: How long does the ELP matrix remain in the joint?

Authors: We did not directly measure ELP following intra-articular delivery. However, IL-1Ra and sTNFRII were detectable at day 5, suggesting that the ELP matrix is likely to still be in the joint $5 \mathrm{~d}$ after an intra-articular injection. Beyond that time, it is unknown whether the matrix still resides in the joint. Previous studies using a non-cross-linked formulation of the ELPs showed that $90 \%$ of a $30 \mu \mathrm{L}$ injected dose of ELP will be cleared by the joint space in $14 \mathrm{~d}$ (Betre et al., 2006a). The cross-linked 
ELP used in our study serves as a unique drug depot, and this is the first report of the intra-articular use of ELPs for drug therapy.

Reviewer I: In Fig. 2 the level of the TNF inhibitor measured in the serum is $30-100 \times$ higher than IL-1Ra, despite $3 \times$ more IL-1Ra being loaded into the ELP matrices. Is this considered a genuine difference or possibly a difference in the sensitivity of the respective ELISAs?

Authors: This measurement is considered a genuine difference, which we speculate arises from the pharmacokinetics of sTNFRII and IL-1Ra. When these drugs clear the joint space after an intra-articular injection, they can be detected in the systemic circulation until they are eliminated from the body. Systemically, sTNFRII has an average elimination half-life of 3-5 d, while IL-1Ra has an average elimination half-life of $3 \mathrm{~h}$ (Nijkamp and Parnham, 2005). Because of the short half-life of these drugs compared to other similar inhibitors, it is preferred to deliver these drugs via intra-articular injection instead of systemically to ensure that the drug reaches its target before it is eliminated.

Reviewer II: Could you better describe the affinity of the ELP to the IL-1Ra and sTNFRII? Can you modulate this interaction so that you can deliver them more precisely temporally?

Authors: IL-1Ra and sTNFRII are not bound to the ELP, but encapsulated through physical entrapment. When the drug solution is mixed with lyophilized cross-linked ELP at $4{ }^{\circ} \mathrm{C}$ and subsequently injected into the joint space at $37^{\circ} \mathrm{C}$, it undergoes an inverse thermal phase transition, causing the ELP to aggregate and form a drug depot inside the joint. This depot then slowly disaggregates, producing a prolonged release therapy. We speculate that the difference in release rate of the two drugs is due to their relative size difference; IL-1Ra has a size of $17.3 \mathrm{kDa}$, whereas sTNFRII has a size of $150 \mathrm{kDa}$.

Reviewer II: Do you envision using added exogenous cells to the delivered material?

Authors: At the present time, there is no plan to add exogenous cells to the delivered material. In previous studies, we have shown that ELP can support chondrogenesis of human adipose-derived adult stem cells without exogenous chondrogenic supplements (Betre et al., 2006b). In other studies by our group, we observed that intra-articular delivery of purified MSCs from C57BL/6 and MRL/MpJ mice prevented PTA after articular fracture, presumably due to an anti-inflammatory effect of the cells (Diekman et al., 2013). A future application could be the delivery of both cells and drugs via ELPs to the knee to improve joint healing after articular fracture.

Reviewer II: How would these results relate to larger animals? Humans?

Authors: The findings of this study show the promising potential of ELPs as an intra-articular drug delivery therapy. The translation of this work to larger animals should simply require scale up of the amount of drug and ELP used to account for the larger joint space of these animals, although the clearance and degradation times may differ in larger animals. Transitioning to humans would require an FDA safety trial, as both ELPs and IL-1Ra are approved for use in human patients. Currently, ELP is being used as a subcutaneous drug depot in a diabetes clinical trial to deliver glucagon-like peptide-1 (Amiram et al., 2013), which would help with transitioning the use of cross-linked ELP from bench to clinic. IL-1Ra is approved for use in RA patients, and when administered intra-articularly following injury, has shown short-term efficacy in reducing pain and improving function scores after ACL tears (Kraus et al., 2012). Further clinical trials would be needed to examine the long-term safety and efficacy of xELP[IL-1Ra] as a therapy for PTA.

\section{Additional References}

Betre H, Ong SR, Guilak F, Chilkoti A, Fermor B, Setton LA (2006b) Chondrocytic differentiation of human adipose-derived adult stem cells in elastin-like polypeptide. Biomaterials 27: 91-99.

Diekman BO, Wu CL, Louer CR, Furman BD, Huebner JL, Kraus VB, Olson SA, Guilak F (2013) Intra-articular delivery of purified mesenchymal stem cells from C57BL/6 or MRL/MpJ superhealer mice prevents posttraumatic arthritis. Cell Transplant 22: 1395-1408.

Nijkamp FP, Parnham MJ (2005) Principles of Immunopharmacology. Birkhäuser Basel, Basel, Chapter C13, p 535.

Piccolo GL, Kaplan DS, Batchelder KF, Kapur R, Kotz RM (1993) Biotechnology-derived biomaterials modulate host cell reactive oxygen production as measured by chemiluminescence. Transactions of the Annual Meeting of the Society for Biomaterials, Birmingham, AL. 